\title{
Upper equatorial Atlantic variability during 2002 and 2005 associated with equatorial Kelvin waves
}

\author{
Verena Hormann ${ }^{1}$ and Peter Brandt ${ }^{1}$ \\ Received 29 August 2008; revised 17 December 2008; accepted 6 January 2009; published 7 March 2009.
}

[1] On the basis of moored $\left(35^{\circ} \mathrm{W}, 0^{\circ}\right.$ and $\left.23^{\circ} \mathrm{W}, 0^{\circ}\right)$ and satellite observations, we contrast the upper equatorial Atlantic variability during 2002 with those during 2005. Inspection of the interannual boreal summer cold tongue variability revealed a warm (cold) event in 2002 (2005), with relaxed (intensified) winds in the west and the Equatorial Undercurrent (EUC) embedded in a shallower (deeper) thermocline at $23^{\circ} \mathrm{W}$. During both years, 2002 and 2005, equatorial Kelvin waves are present in moored observations as $20^{\circ} \mathrm{C}$ isotherm depth anomalies and dynamic height anomalies. Basin-wide sea surface height anomalies are used to derive an equatorial Kelvin wave mode. The time evolution of this mode represents the basis for a regression analysis to investigate related oceanic variability: Compared to the exceptionally strong wave activity in 2002, equatorial Kelvin waves were generally weaker during 2005. The main effect of equatorial Kelvin waves on zonal velocity anomalies at $23^{\circ} \mathrm{W}, 0^{\circ}$ is evident well below the EUC core. Their direct influence on cold tongue sea surface temperature is small, but they are found to affect the equatorial thermocline slope. Prior to the cold tongue onset in 2002 (2005), the presence of equatorial Kelvin waves is associated with a flattened (steeper) thermocline slope that is crucial for the shallowing (deepening) of the EUC core at $23^{\circ} \mathrm{W}$ and that might precondition the development of the warm (cold) event.

Citation: Hormann, V., and P. Brandt (2009), Upper equatorial Atlantic variability during 2002 and 2005 associated with equatorial Kelvin waves, J. Geophys. Res., 114, C03007, doi:10.1029/2008JC005101.

\section{Introduction}

[2] Climate fluctuations in the tropical Atlantic sector are dominated by two distinct patterns of coupled oceanatmosphere variability. These modes of variability, collectively referred to as tropical Atlantic variability (TAV), are tightly phase locked to the pronounced Atlantic seasonal cycle and vary on interannual to decadal timescales. During boreal spring, when the equatorial Atlantic is uniformly warm, conditions are favorable for the development of an interhemispheric gradient of sea surface temperature (SST) anomalies often referred to as the meridional mode. The so-called zonal mode is frequently viewed as the Atlantic counterpart of the Pacific El Niño Southern Oscillation (ENSO) and is most pronounced during boreal summer coinciding with the seasonal development of the eastern equatorial cold tongue [e.g., Weare, 1977; Merle et al., 1980; Xie and Carton, 2004; Kushnir et al., 2006; Chang et al., 2006].

[3] Like the Pacific ENSO mode, the underlying feedback in the Atlantic zonal mode is also thought to be the dynamical Bjerknes [1969] mechanism [e.g., Zebiak, 1993; Xie and Carton, 2004; Chang et al., 2006; Keenlyside and Latif, 2007]. Although the growth rate in the Atlantic is up

\footnotetext{
${ }^{1}$ IFM-GEOMAR, Leibniz-Institut für Meereswissenschaften, Kiel, Germany.

Copyright 2009 by the American Geophysical Union. 0148-0227/09/2008JC005101\$09.00
}

to $50 \%$ smaller compared to the Pacific, the Bjerknes feedback was found to be strong during boreal spring and summer [Keenlyside and Latif, 2007]. Because of the weaker net feedback, other mechanisms can also contribute to SST variability in the eastern equatorial Atlantic: (1) there may be a possible link between the two TAV modes as first suggested by Servain et al. [1999], and (2) ENSO may act as a remote forcing of equatorial Atlantic variability [e.g., Carton and Huang, 1994; Latif and Grötzner, 2000].

[4] Wyrtki [1975] early proposed that long equatorial waves play a fundamental role in the context of ENSO. During the extensively studied Atlantic warm event in 1984 that revealed in many respects conditions similar to those during an El Niño [e.g., Philander, 1986; Katz et al., 1986; Hisard et al., 1986; Weisberg and Colin, 1986], Katz [1987] also observed prominent eastward propagations along the equator with first baroclinic mode Kelvin wave characteristics. However, Carton and Huang [1994] pointed out that the role of subsurface ocean dynamics can be different during individual Atlantic warm events: By contrasting responses of a model simulation to the observed wind changes during 1983/84 and 1987/88, they showed that the subsurface ocean played a preconditioning role for the warm event in 1984 while such a role was not evident for the warm event in 1988.

[5] Substantial progress in the description of equatorial waves has been made with the availability of altimeter measurements: First attempts to fit meridional equatorial wave modes to altimetric sea surface height ( $\mathrm{SSH}$ ) data took 
place in the Pacific to investigate the ENSO phenomenon [e.g., Delcroix et al., 1991]. In the Atlantic, equatorial waves and their seasonal timescales have been described at an early stage from altimeter measurements [e.g., Arnault et al., 1992] while their interannual timescales have only more recently been established by França et al. [2003]. In addition, the existence of altimetric data allowed Katz [1997] to further investigate the Kelvin wave signal as observed during the warm event in 1984 [Katz, 1987]. His analysis revealed enhanced variance of sea surface displacemets in two period bands centered around 50 and 25 days, with the 50-day variability attributed to eastward propagating Kelvin waves of first baroclinic mode. A detailed examination of the dynamics within the intraseasonal window at 40-60 days was just recently carried out by Han et al. [2008]: The strong 40-60 day SSH and thermocline variability within the near-equatorial region was found to result mainly from first and second baroclinic mode equatorial Kelvin waves that are forced by intraseasonal zonal winds.

[6] However, equatorial Kelvin waves also cause perturbations in the zonal current field. A model study by Seidel and Giese [1999] showed that the passage of these waves at the onset of the 1997/98 El Niño event was associated with an initial strengthening of the Pacific Equatorial Undercurrent (EUC) followed by a rapid shutdown. Such a weakening of the EUC during El Niño was first noted by Firing et al. [1983] and attributed to an adjustment of the EUC to the relaxed zonal pressure gradient created by the westerly wind anomalies in the western and central Pacific. Using direct shipboard velocity measurements, Johnson et al. [2002] were able to present a detailed description of the Pacific EUC behavior including the deepening/shoaling of the EUC in the East/West Pacific together with a northward shift of the current core in the central Pacific during El Niño. Although model studies of the Atlantic EUC also clearly indicate a weakening (strengthening) of the EUC during warm (cold) events [Góes and Wainer, 2003; Hormann and Brandt, 2007], the observations by Hisard and Henin [1987] during the warm event in 1984 revealed that the EUC appeared to remain relatively strong and to penetrate nearly to the eastern boundary at the peak of this event.

[7] The objective of this study is to investigate the upper equatorial Atlantic variability associated with equatorial Kelvin waves (section 4) within the context of the interannual boreal summer variability (section 3 ), i.e., we contrast here a warm event in 2002 with a cold event in 2005. A complete description of the used moored and satellite observations is provided in section 2 . Finally, the results are summarized and discussed in section 5 .

\section{Data}

\subsection{Mooring Data}

[8] In this study, data from two equatorial current meter moorings at $35^{\circ} \mathrm{W}$ and $23^{\circ} \mathrm{W}$ are used together with data from nearby Prediction and Research Moored Array in the Atlantic (PIRATA, http://www.pmel.noaa.gov/pirata) moorings [Servain et al., 1998]. The current meter mooring at $35^{\circ} \mathrm{W}$ was deployed in August 2004 and finally recovered in June 2006. At about 150-m depth, two acoustic Doppler current pofilers (ADCPs) looking up- and downward, with a typical measurement range of $350 \mathrm{~m}$ each, were in use. The first current meter mooring at $23^{\circ} \mathrm{W}$, consisting (among other instruments) of one upward looking ADCP at about 130-m depth, was deployed in December 2001 and recovered in December 2002 within the framework of the PIRATA program [e.g., Provost et al., 2004; Giarolla et al., 2005]. The successive second and third deployment periods began in February 2004 and lasted to June 2006. During these deployment periods, the mooring was equipped with both an up- and a downward looking ADCP covering the water column from the near-surface down to about $700 \mathrm{~m}$. Unfortunately, a reexamination of the raw data revealed an erroneous behavior of two of the four beams of the upward looking ADCP used during the second deployment period from February 2004 to May 2005 [see Brandt et al., 2006]. These data are excluded here and further information about the basic instrumentation and data processing are found in Brandt et al. [2008] as well as von Schuckmann et al. [2008].

[9] At the PIRATA moorings, temperature is recorded at 11 depths between $1 \mathrm{~m}$ and $500 \mathrm{~m}$, with $20-\mathrm{m}$ spacing in the upper $140 \mathrm{~m}$. In this study, daily values at $23^{\circ} \mathrm{W}, 0^{\circ}$ are used and gaps are filled by a Langrangian interpolation algorithm as also applied to the velocity gap of about $30 \mathrm{~m}$ arising from the separation of the two ADCP transducers [see Brandt et al., 2008; von Schuckmann et al., 2008]. Besides we make use of the daily $20^{\circ} \mathrm{C}$ isotherm depth and dynamic height data at the equator, $35^{\circ} \mathrm{W}$ and $23^{\circ} \mathrm{W}$ as provided by the PIRATA project. Note that corresponding time series farther east are very gappy during the current meter deployment periods, in particular nearly no data are available in 2002, and thus data from equatorial PIRATA moorings at $10^{\circ} \mathrm{W}$ and $0^{\circ} \mathrm{E}$ are not considered here. The depth of the $20^{\circ} \mathrm{C}$ isotherm was calculated from temperature profiles using linear interpolation of depth versus temperature and dynamic heights were computed from temperature profiles by vertically integrating the specific volume anomaly from the surface to 500-m depth, resulting in dynamic heights at the sea surface referenced to 500 decibars [Servain et al., 1998].

\subsection{Satellite Data}

[10] In order to investigate basin-wide structures, satellite products of SSH, surface wind stress and SST are used here. Multimission gridded SSHs, generated by the SSALTO/ DUACS altimeter data processing software and computed with respect to a 7-year mean, are obtained from Archiving, Validation and Interpretation of Satellite Oceanographic data (AVISO, http://www.aviso.oceanobs.com). The horizontal resolution is regularly $1 / 3^{\circ} \times 1 / 3^{\circ}$ on a Mercator grid, while the temporal resolution is 7 days prior to midFebruary 2003 and 3 to 4 days thereafter. Daily surface wind stress fields, as retrieved from the NASA SeaWinds scatterometer on board QuikSCAT, are provided by the Centre de Recherche et d'Exploitation Satellitaire (CERSAT, http://cersat.ifremer.fr) on global $1 / 2^{\circ} \times 1 / 2^{\circ}$ resolution geographical grids. In order to reconstruct gap-filled and averaged synoptic fields from discrete observations, a statistical interpolation was performed at CERSAT using an objective method. Besides, daily Microwave Optimally Interpolated SST data based on the microwave imager on board the Tropical Rainfall Measuring Mission (TRMM) 

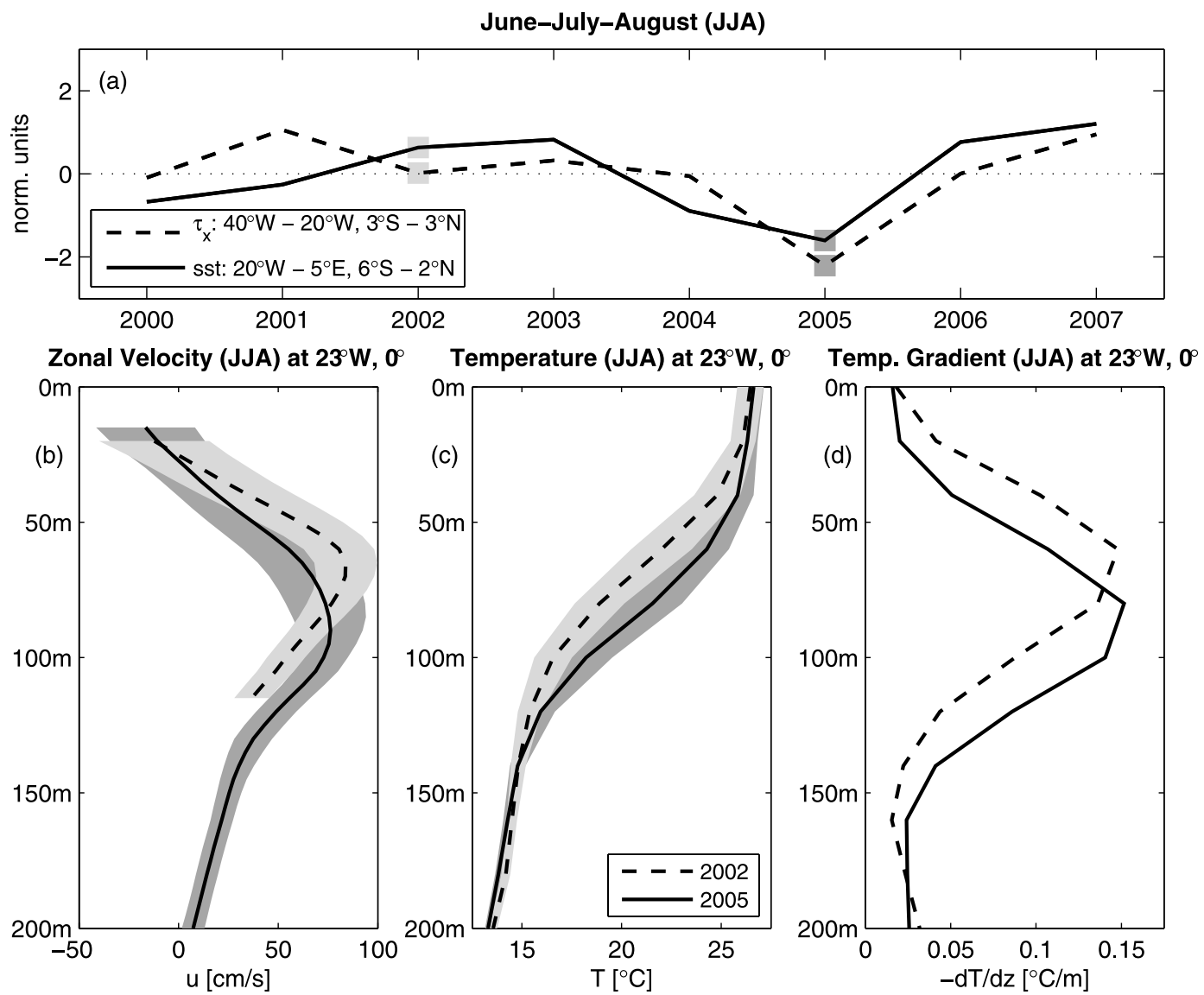

Figure 1. (a) June-July-August averages of SST over the region $20^{\circ} \mathrm{W}-5^{\circ} \mathrm{E}, 6^{\circ} \mathrm{S}-2^{\circ} \mathrm{N}$ (solid) and zonal wind stress over the region $40^{\circ} \mathrm{W}-20^{\circ} \mathrm{W}, 3^{\circ} \mathrm{S}-3^{\circ} \mathrm{N}$ (dashed), with the zero line dotted; normalized by standard deviation. The years 2002 and 2005 are marked. (b) Mean June-July-August zonal velocity $(\mathrm{cm} / \mathrm{s})$ at $23^{\circ} \mathrm{W}, 0^{\circ}$, with standard deviation (shaded) during 2002 (dashed line, light gray shading) and 2005 (solid line, dark gray shading); mean flow calculated by subtracting annual and semiannual harmonics. (c) Same as Figure $1 \mathrm{~b}$ but for temperature $\left({ }^{\circ} \mathrm{C}\right)$ at $23^{\circ} \mathrm{W}, 0^{\circ}$. (d) Temperature gradient $\left({ }^{\circ} \mathrm{C} / \mathrm{m}\right)$ corresponding to Figure 1c.

satellite are used here. The gridded SST fields as provided at http://www.remss.com were derived by blending together the available data using the optimum interpolation scheme described by Reynolds and Smith [1994], with a horizontal resolution of $1 / 4^{\circ} \times 1 / 4^{\circ}$.

[11] These satellite data sets are finally mapped on a common 3.5-day temporal and $1 / 2^{\circ} \times 1 / 2^{\circ}$ spatial grid using linear interpolation in time and a Gaussian interpolation scheme in space, with coastal regions less than $500 \mathrm{~m}$ deep discarded.

[12] Anomalies, as hereinafter referred to, are computed by subtracting the mean plus annual and semiannual harmonics of both the respective satellite and (as far as available) mooring data for the period end-August 2001 to December 2006.

\section{Interannual Boreal Summer Variability}

\subsection{Surface Conditions}

[13] The interannual boreal summer SST variability in the eastern Atlantic cold tongue and the corresponding zonal wind stress variability in the western and central part of the basin are presented in terms of June-July-August averages over the respective regions (Figure 1a) [see Hormann and Brandt, 2007]. In general, warm (cold) events in the east are linked with reduced (increased) easterlies toward the west which is in good agreement with previous studies [e.g., Servain et al., 1982; Zebiak, 1993]. The oceanic adjustment to changes in the wind involves the presence of wind-driven waves [e.g., Cane and Sarachik, 1976, 1977; Moore and Philander, 1977; Philander and Pacanowski, 1986]. A recent study by Han et al. [2008] showed that intraseasonal equatorial Kelvin waves dominated sea level and thermocline variability throughout the equatorial Atlantic. Particularly strong Kelvin waves were observed during boreal spring 2002 having a spectral peak at 40-60 days. In order to further investigate the upper equatorial Atlantic variability associated with equatorial Kelvin waves within the context of the interannual boreal summer variability, we contrast here the warm year 2002 with the coldest year on record 2005.

[14] Figure 2 illustrates the evolution of the different surface conditions prevailing during these events: In boreal spring 2002, large positive SST anomalies (up to $2^{\circ} \mathrm{C}$ ) appear in the eastern cold tongue region while the corresponding pattern during 2005 resembles that of a 

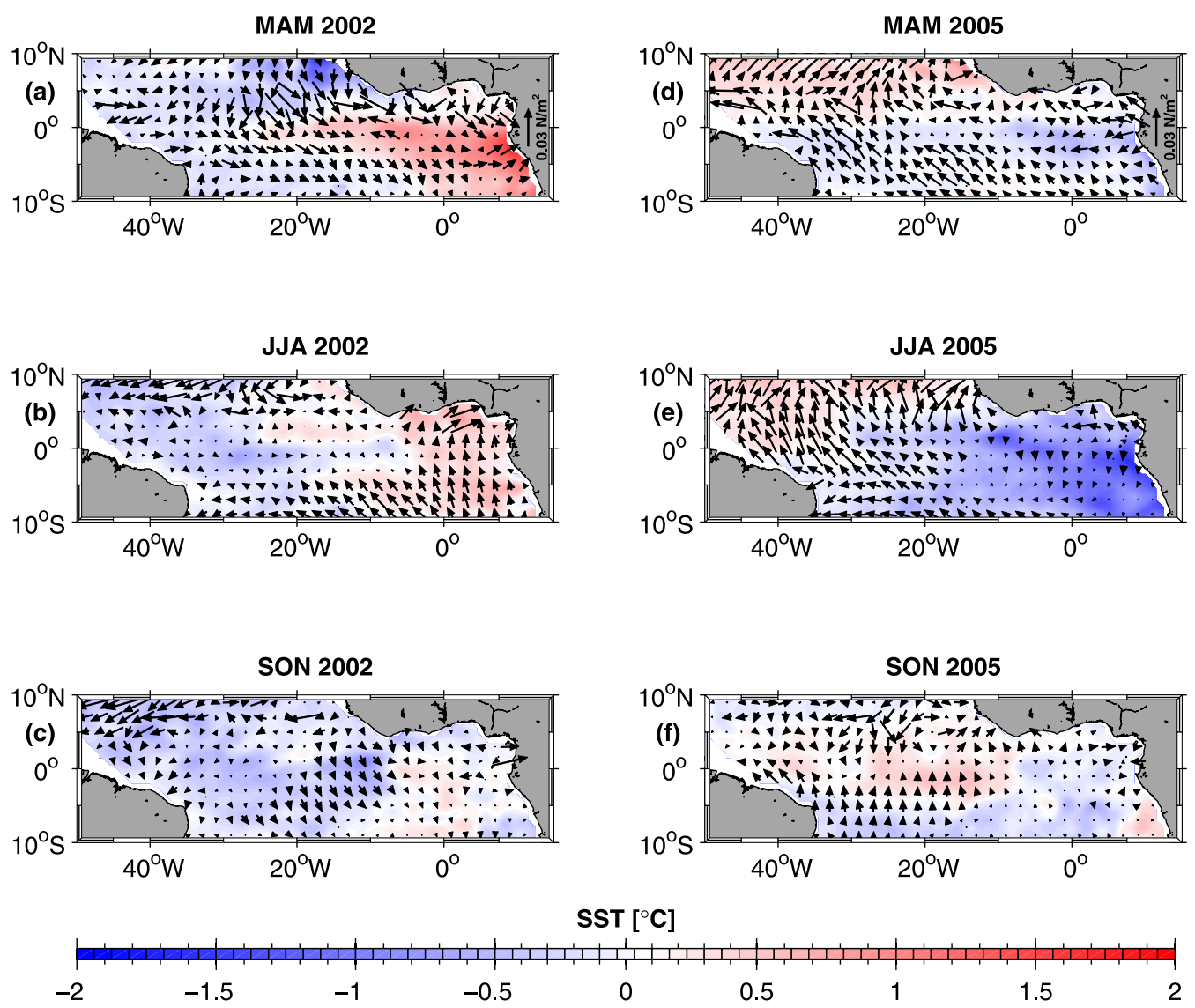

Figure 2. (a, c) March-April-May (MAM), (b, e) June-July-August (JJA), and (c, f) SeptemberOctober-November (SON) averages of SST anomalies $\left({ }^{\circ} \mathrm{C}\right.$; color coded) and zonal wind stress anomalies $\left(\mathrm{N} / \mathrm{m}^{2}\right.$; vectors, with scale indicated in Figures $2 \mathrm{a}$ and $\left.2 \mathrm{c}\right)$ for the years $(\mathrm{a}-\mathrm{c}) 2002$ and $(\mathrm{d}-\mathrm{f}) 2005$.

dipole, with cold (warm) SST anomalies south (north) of the equator [see Foltz and McPhaden, 2006, Figure 2b]. Considering the respective wind stress fields, reduced (enhanced) easterlies are found in the western and central equatorial Atlantic during 2002 (2005); note that anomalies are strongest in the central (western) part of the basin during boreal spring 2002 (2005). The easterlies are then around normal conditions in this region during boreal summer 2002, but still enhanced in 2005. Compared to the boreal spring situation, SST anomalies in the cold tongue region are reduced (enhanced) during boreal summer 2002 (2005) and a strong cooling of up to $2^{\circ} \mathrm{C}$ is now observable in 2005. During boreal fall, anomalies are generally small for both years.

[15] However, the evolution of the surface conditions points to a possible relation between the meridional and zonal mode during 2005 as first suggested by Servain et al. [1999]. Although the Northern Hemisphere was on the whole anomalously cold during boreal spring 2002, the large zonal gradient of southern hemisphere SST anomalies is here not characteristic for the meridional mode.

\subsection{Moored Observations}

[16] In order to illustrate the subsurface differences between 2002 and 2005, mean boreal summer profiles at the equator, $23^{\circ} \mathrm{W}$ are calculated from the moored observations (Figures $1 \mathrm{~b}-1 \mathrm{~d}$ ).
[17] The mean boreal summer zonal velocity profiles reveal a somewhat stronger and shallower EUC core in $2002(84 \pm 16 \mathrm{~cm} / \mathrm{s}, 65 \mathrm{~m})$ than in $2005(76 \pm 16 \mathrm{~cm} / \mathrm{s}$, $90 \mathrm{~m}$ ). Additionally, the mean boreal summer temperature profiles reveal a deepening of the isotherms in the depth range 40-120 m during 2005 compared to 2002. Considering the associated vertical temperature gradients, the EUC is found to be embedded in a shallower (deeper) thermocline during 2002 (2005).

[18] The observed differences are also obvious as regards the corresponding zonal velocity anomalies from March to November. Using the depth of the $20^{\circ} \mathrm{C}$ isotherm as an indicator for thermocline depth, positive anomalies prevail above the shallow thermocline during boreal summer 2002 (Figure 3a) while largely negative values are found above the deeper thermocline during boreal summer 2005 (Figure 3b). In contrast to $23^{\circ} \mathrm{W}$, where anomalies are most pronounced above the thermocline, distinct negative zonal velocity anomalies are observable down to $200-\mathrm{m}$ depth at $35^{\circ} \mathrm{W}$ during boreal summer 2005 (Figure 3c).

[19] Basically, the shallowing (deepening) of the EUC core during warm (cold) events is consistent with the dynamics of the EUC driven by the eastward zonal pressure gradient force [e.g., Philander and Pacanowski, 1986; Wacongne, 1989]. The observations are also in general agreement with model studies by Góes and Wainer [2003] 
Zonal Velocity Anomaly at $23^{\circ} \mathrm{W}, 0^{\circ}$

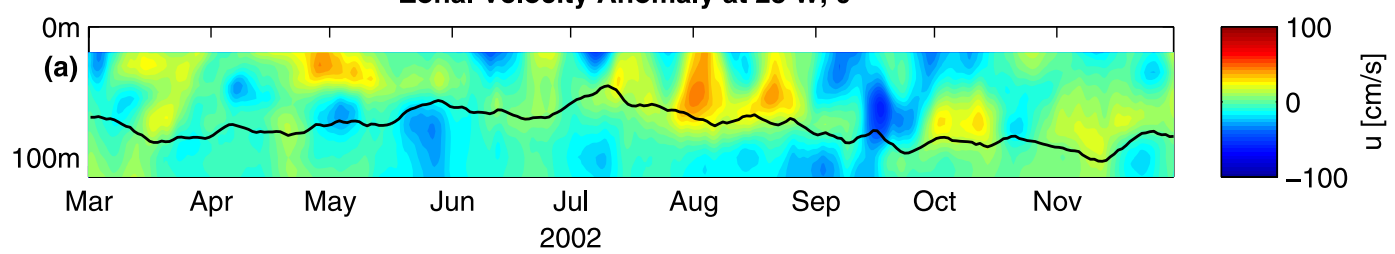

Zonal Velocity Anomaly at $23^{\circ} \mathrm{W}, 0^{\circ}$



Figure 3. (a) Zonal velocity anomalies $(\mathrm{cm} / \mathrm{s})$ at $23^{\circ} \mathrm{W}, 0^{\circ}$ from March to November 2002, with marked the $20^{\circ} \mathrm{C}$ isotherm depth (black line) to indicate thermocline depth. (b) Same as Figure 3a but for 2005. (c) Same as Figure $3 \mathrm{~b}$ but at $35^{\circ} \mathrm{W}, 0^{\circ}$. Data are smoothed by a 7-day running mean.

and Hormann and Brandt [2007] revealing a shallower (deeper) structure of the EUC during warm (cold) events.

\section{Equatorial Kelvin Waves}

\subsection{Moored Observations}

[20] In order to document the presence of equatorial Kelvin waves during both the warm event in 2002 and the strong cold event in 2005 , the available moored $20^{\circ} \mathrm{C}$ isotherm depth (Figures $4 \mathrm{a}$ and $4 \mathrm{~d}$ ) and dynamic height anomalies (Figures $4 \mathrm{~b}$ and $4 \mathrm{e}$ ) at $35^{\circ} \mathrm{W}, 0^{\circ}$ and $23^{\circ} \mathrm{W}, 0^{\circ}$ are considered for the respective March to November periods. These time series are found to be highly correlated (correlation coefficient $c c \sim 0.9$, with $95 \%$ significance level of 0.13 ) at both locations during 2002 and 2005.

[21] Besides, reasonable correlations are found between $20^{\circ} \mathrm{C}$ isotherm depth anomalies and EUC core depth anomalies $\left(c c=0.54 / 0.38\right.$ at $23^{\circ} \mathrm{W}, 0^{\circ}$ during March/June to November $2002 / 2005$ and $c c=0.47$ at $35^{\circ} \mathrm{W}, 0^{\circ}$ during March to November 2005), and dynamic heights are closely related to SSHs at the two mooring sites (not shown).

[22] As stated by Rebert et al. [1985] for the tropical Pacific, dynamic height and sea level fluctuations agree only in those areas where the thermal structure resembles a two-layer system very well and sea level fluctuations were as well observed to be a good measure of thermocline depth variations.

[23] Cold tongue SSH and SST anomalies are also well correlated with each other during 2002 ( $c c=0.72,95 \%$ significance level is 0.22 ), with positive anomalies prevailing around mid-May related to the warm event (Figure 4c). During 2005, the correlation of the two variables drops to 0.50 and large discrepancies are found from mid-May to midJuly when SST anomalies are strongest negative (Figure 4f).

[24] França et al. [2003] already noted a partial lack of correspondence between SSH and SST anomalies in the equatorial region. The propagation of equatorial Kelvin waves from the western basin into the eastern basin could be followed in the SSH data, but not in the SST data. As the SSHs can mainly be attributed to dynamical effects, the observed differences between SSH and SST in the cold tongue region during boreal summer 2005 suggest that the influence of ocean dynamics on SST might be of minor importance.

[25] However, considering lagged correlations of the equatorial $20^{\circ} \mathrm{C}$ isotherm depth anomalies and dynamic height anomalies at $35^{\circ} \mathrm{W}$ with their respective counterparts at $23^{\circ} \mathrm{W}$ (Table 1), significantly larger coefficients are obtained for 2002 than 2005. The lags $(\mathrm{d} t)$ of maximum correlation are then used to estimate corresponding phase velocities

$$
c=\mathrm{d} x / \mathrm{d} t
$$

with $\mathrm{d} x$ here the distance between $35^{\circ} \mathrm{W}, 0^{\circ}$ and $23^{\circ} \mathrm{W}, 0^{\circ}$. Apart from the 2005-dynamic height case, where pronounced differences are obvious between the $35^{\circ} \mathrm{W}$ and $23^{\circ} \mathrm{W}$ time series and correlation is lowest $(c c=0.38)$, the calculated phase velocities are around $1.4 \mathrm{~m} / \mathrm{s}$ eastward. 

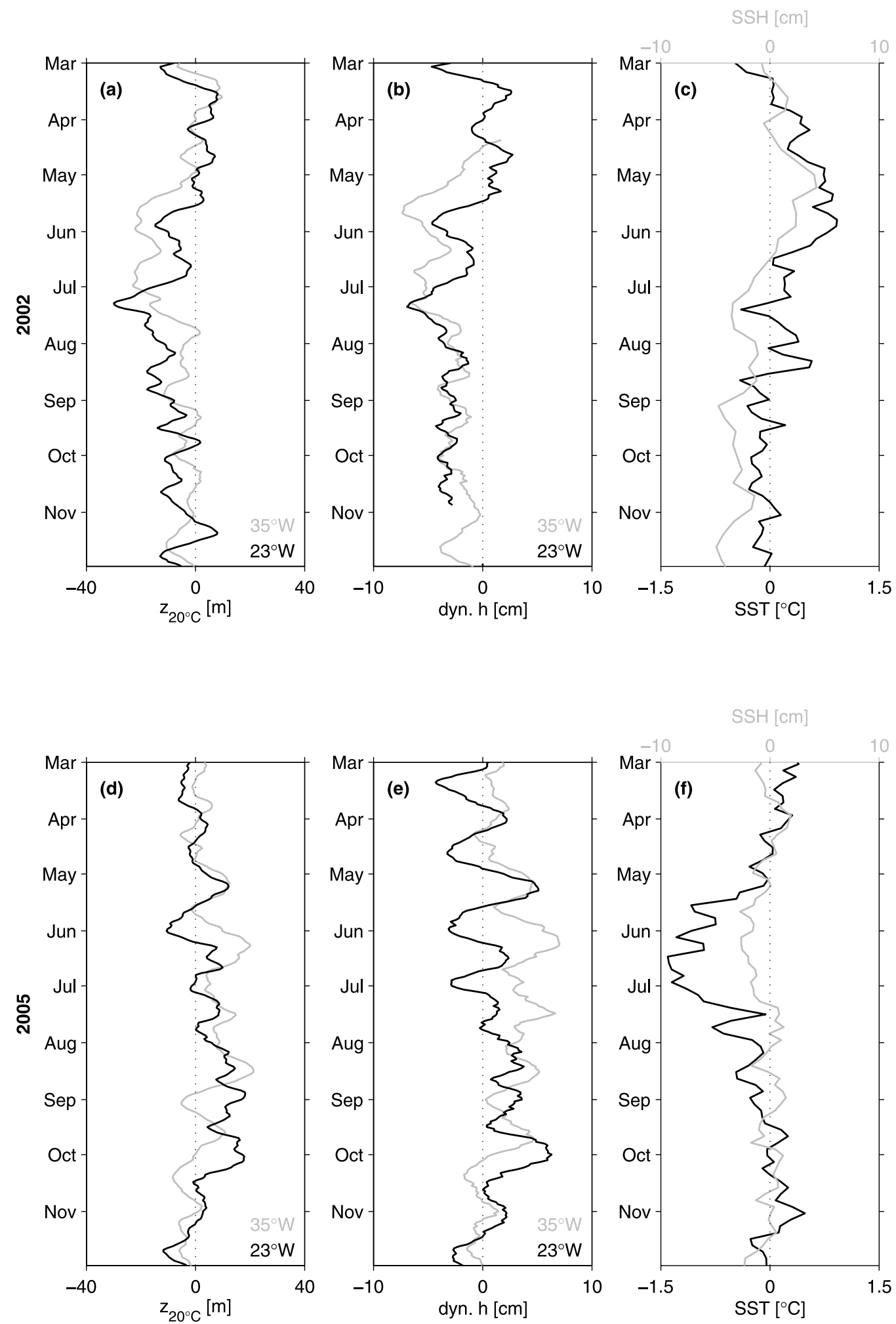

Figure 4. (a) Time series of $20^{\circ} \mathrm{C}$ isotherm depth anomalies at $35^{\circ} \mathrm{W}, 0^{\circ}$ (m; gray) and $23^{\circ} \mathrm{W}, 0^{\circ}$ (m; black) from March to November 2002; positive values indicate a deeper thermocline. Data are smoothed by a 7-day running mean. (b) Same as Figure 4a but for dynamic height anomalies (cm). (c) Time series of SSH (cm; gray) and SST $\left({ }^{\circ} \mathrm{C}\right.$; black) anomalies averaged over the region $20^{\circ} \mathrm{W}-5^{\circ} \mathrm{E}$, $6^{\circ} \mathrm{S}-2^{\circ} \mathrm{N}$ from March to November 2002. (d-f) Same as Figures $4 \mathrm{a}-4 \mathrm{c}$ but for 2005. 
Table 1. Maximum Lagged Correlation Coefficients and Corresponding Lags of Equatorial $20^{\circ} \mathrm{C}$ Isotherm Depth Anomalies $\left(\mathrm{z}_{20^{\circ} \mathrm{C}}\right)$ and Dynamic Height Anomalies (dyn. h) at $35^{\circ} \mathrm{W}, 0^{\circ}$ With Their Respective Counterparts at $23^{\circ} \mathrm{W}, 0^{\circ a}$

\begin{tabular}{ccccc}
\hline $\begin{array}{c}\text { Year } \\
\text { (Mar-Nov) }\end{array}$ & Variable & $\begin{array}{c}\text { Max. } \\
\text { Correlation }\end{array}$ & $\begin{array}{c}\text { Max. } \\
\text { Correlation } \\
\text { Lag (days) }\end{array}$ & $\begin{array}{c}\text { Phase } \\
\text { Velocity } \\
(\mathrm{m} / \mathrm{s})\end{array}$ \\
\hline 2002 & $\mathrm{z}_{20{ }^{\circ} \mathrm{C}}$ & 0.62 & 12 & 1.3 \\
2002 & $\mathrm{dyn}^{\circ} \mathrm{h}$ & 0.58 & 11 & 1.4 \\
2005 & $\mathrm{Z}_{20}{ }^{\circ} \mathrm{C}$ & 0.47 & 10 & 1.5 \\
2005 & dyn. h & 0.38 & 7 & 2.2 \\
\hline
\end{tabular}

${ }^{a}$ According to the time series shown in Figures 4a, 4b, 4d and 4e; 95\% significance level is 0.13 . The estimated phase velocities are also given (see text for details).

[26] These estimates agree well with theoretical values of the second baroclinic equatorial Kelvin wave mode as derived from a vertical mode decomposition of the mean stratification at $35^{\circ} \mathrm{W}, 0^{\circ}$ and near $23^{\circ} \mathrm{W}, 0^{\circ}$ by use of the available ship sections at these locations (see the work of Hormann and Brandt [2007, Table 1]; updated by the latest surveys along $23^{\circ} \mathrm{W}$ of RV Ron Brown during June to July 2006 and RV L'Atalante during February/March 2008) (Table 2). Comparable values were also reported in recent studies by Illig et al. [2004, Table 1], Schouten et al. [2005] and Han et al. [2008, Table 1].

\subsection{Basin-Wide Characteristics}

[27] In order to investigate the equatorial Kelvin waves in a basin-wide context, the available satellite observations of SSHs are now considered in detail. Figure 5 illustrates apparent eastward propagating $\mathrm{SSH}$ anomalies along the equator which are superimposed on a strong seasonal cycle [see e.g., Arnault et al., 1992; Schouten et al., 2005]. The $\mathrm{SSH}$ anomalies also mirror the general features of the boreal summer extreme events as shown in Figure 1a, with prevailing positive (negative) values in the cold tongue region during warm (cold) events [see e.g., França et al., 2003].

[28] The wind-driven characteristics of these eastward propagations are illustrated by performing a lagged correlation analysis between zonal wind stress anomalies in the west (Figure 6a, same wind region as in Figure 1a) and SSH anomalies in the entire equatorial basin. Significant positive maximum correlation coefficients are found along the equator from about $30^{\circ} \mathrm{W}$ toward the African coast and an eastward phase propagation along the equator is obvious (Figures $6 \mathrm{~b}$ and $6 \mathrm{c}$ ). The corresponding propagation velocity can be estimated to $1.6 \mathrm{~m} / \mathrm{s}$ (see equation (1)) which is again close to the theoretical value of the second baroclinic Kelvin wave mode (see Table 2). As regards the equatorial region to the west of about $30^{\circ} \mathrm{W}$ where positive correlations are insignificant or negative correlations are present [see Han et al., 2008, Figure 13], the SSH variability is here generally lower than in the regions farther east along the equator as well as northward and southward along the African coast (Figure 6d). High SSH variability at the western boundary and along $5^{\circ} \mathrm{N}$ is associated with the North Brazil Current (NBC) retroflection/generation of NBC rings and the instability of the North Equatorial Countercurrent [e.g., Schouten et al., 2005, Figure 3; von Schuckmann et al., 2008, Figure 1].
[29] However, zonal wind stress anomalies in the west appear to play an important role in forcing equatorial Kelvin waves as was also most recently suggested by Han et al. [2008]. In addition, Han et al. [2008] noted a particularly strong correlation between zonal wind anomalies in the central-western equatorial basin and anomalous sea levels across the equatorial basin during 2002.

\subsubsection{Kelvin Wave Fit}

[30] The equatorial SSH variability, strongly indicating the presence of equatorial Kelvin waves, will now be discussed in terms of the linear equatorial wave theory [Matsuno, 1966].

[31] First, the phase velocity of the SSH anomalies along the equator for the period end-August 2001 to December 2006 is computed in a more rigorous manner. Figure 7 shows the lagged correlation of $\mathrm{SSH}$ anomalies along the equator with $\mathrm{SSH}$ anomalies at $35^{\circ} \mathrm{W}, 0^{\circ}$ and $23^{\circ} \mathrm{W}, 0^{\circ}$. Second order interpolation is used to determine the exact lag of maximum correlation at each longitude. The linear slopes of the obtained lags with respect to longitude are then given by a least-square fit calculated by using only lags corresponding to maximum correlation coefficients larger than 0.2 . These slopes define the respective phase velocities (see equation (1)). We obtained $1.8 \mathrm{~m} / \mathrm{s}$ for the $35^{\circ} \mathrm{W}$ case and $2.0 \mathrm{~m} / \mathrm{s}$ for the $23^{\circ} \mathrm{W}$ case which are somewhat higher values than the above estimates and fall within the range between the first and second baroclinic mode of equatorial Kelvin waves (see Table 2). Note that the SSH is most sensitive to the lowest baroclinic modes as for higher baroclinic modes the canceling effect of positive and negative isopycnal displacements within the water column increases. The difference between the satellite and moored observations can be understood by considering normalized density perturbation modes which yield larger (factor of about 1.4) steric height (i.e., SSH) amplitudes of the first compared to the second mode, while the vertical displacement in the depth range of the $20^{\circ} \mathrm{C}$ isotherm is smaller (factor of about 2.5) for the first compared to the second mode (not shown). However, the obtained basin-wide phase velocities are in good agreement with previously reported values based on altimeter measurements [e.g., Katz, 1997; França et al., 2003; Han et al., 2008; Polo et al., 2008].

[32] Using an average phase velocity of $c=1.9 \mathrm{~m} / \mathrm{s}$, the equatorial Atlantic SSH anomalies are fitted in a leastsquare sense to the theoretical meridional $(y)$ structure of equatorial Kelvin waves

$$
\eta(y)=\eta_{0} \exp \left(-\beta y^{2} / 2 c\right)
$$

with $\beta=\mathrm{d} f / \mathrm{d} y=2.28 \times 10^{-11} \mathrm{~m}^{-1} \mathrm{~s}^{-1}$ and $f$ the Coriolis parameter; i.e., we minimized the cost function

Table 2. Theoretical Phase Velocities of the First Three Baroclinic Modes as Estimated From a Vertical Mode Decomposition at $35^{\circ} \mathrm{W}, 0^{\circ}$ and $\mathrm{Near} 23^{\circ} \mathrm{W}, 0^{\circ}$

\begin{tabular}{lcc}
\hline & $35^{\circ} \mathrm{W}, 0^{\circ}$ & $\sim 23^{\circ} \mathrm{W}, 0^{\circ}$ \\
\hline 1. Baroclinic mode & $2.5 \mathrm{~m} / \mathrm{s}$ & $2.4 \mathrm{~m} / \mathrm{s}$ \\
2. Baroclinic mode & $1.5 \mathrm{~m} / \mathrm{s}$ & $1.4 \mathrm{~m} / \mathrm{s}$ \\
3. Baroclinic mode & $1.0 \mathrm{~m} / \mathrm{s}$ & $0.9 \mathrm{~m} / \mathrm{s}$ \\
\hline
\end{tabular}




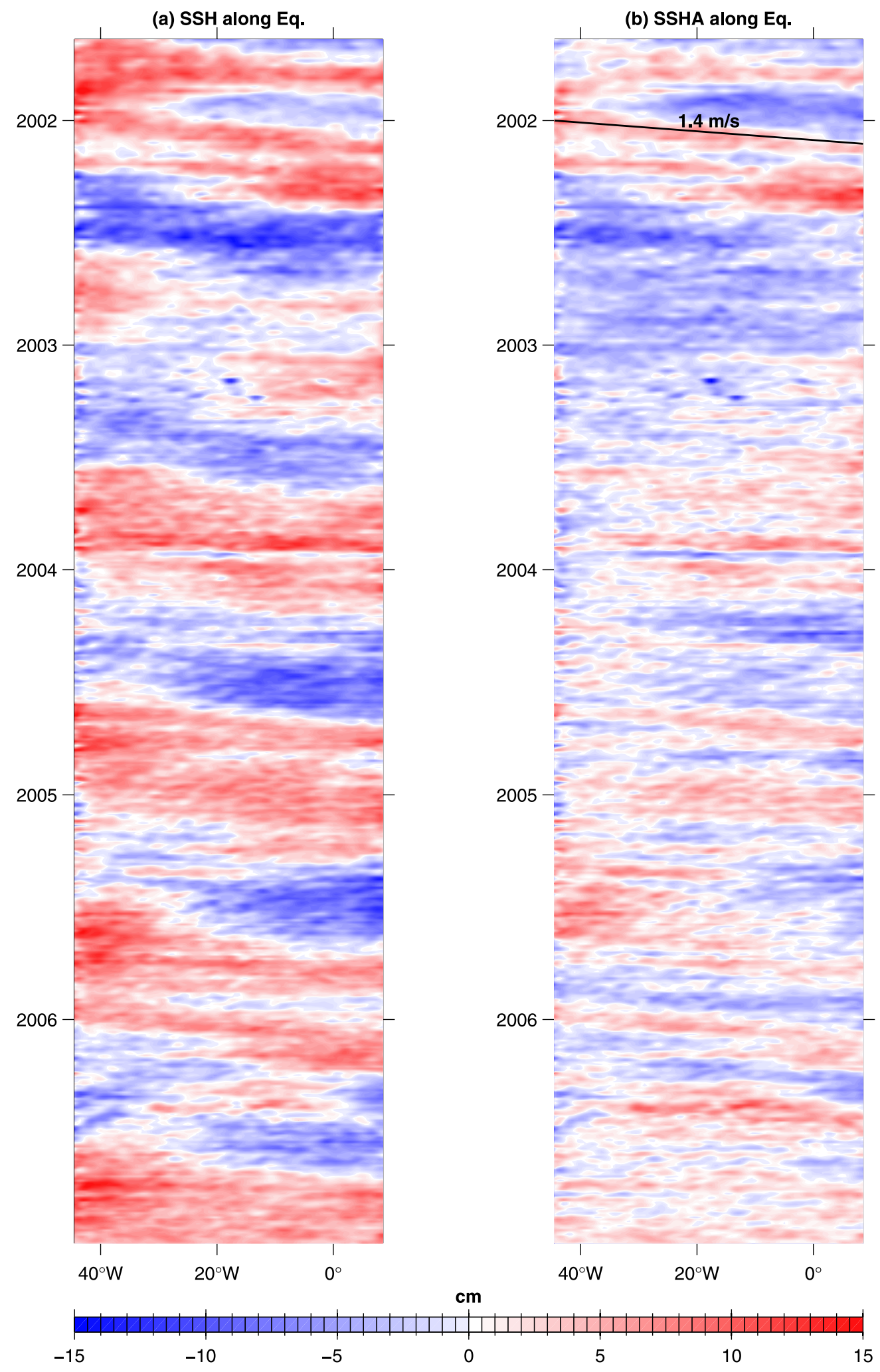

Figure 5. (a) SSH (cm) and (b) corresponding anomalies (cm) along the equator. The phase velocity of $1.4 \mathrm{~m} / \mathrm{s}$ eastward (see Table 1 ) is marked by a black line in Figure $5 \mathrm{~b}$. 

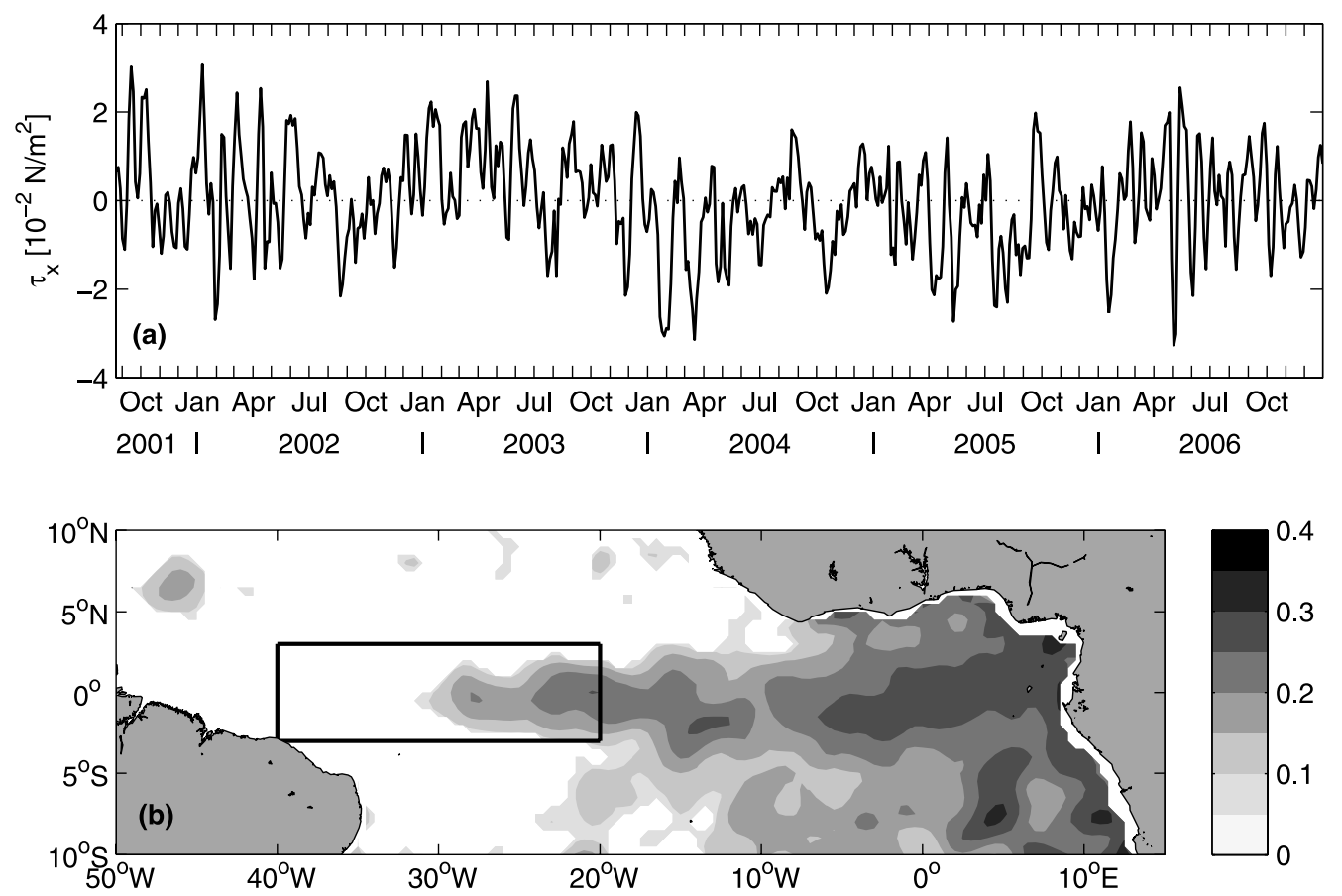

듬
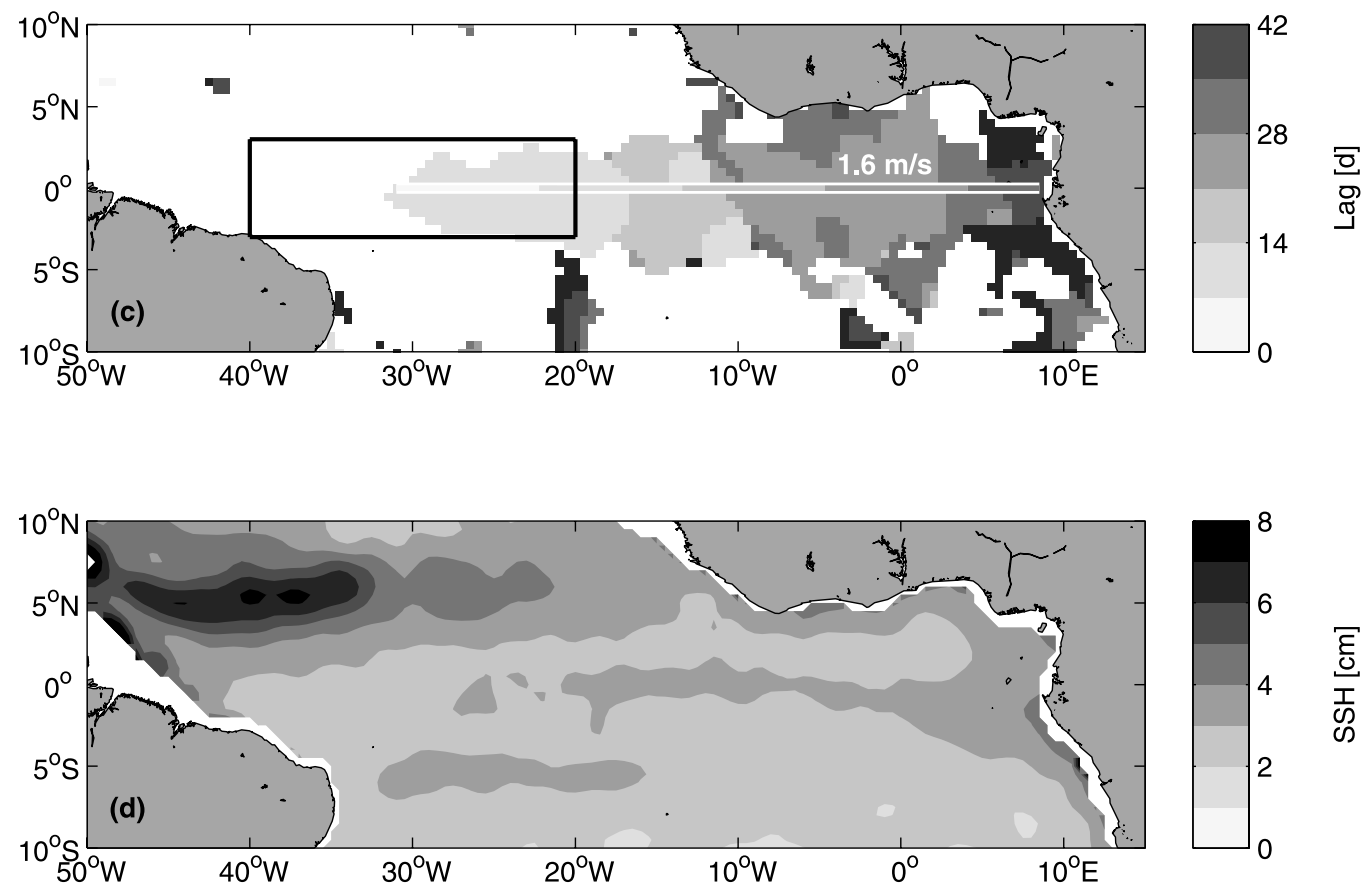

E
エ
ऽ

Figure 6. (a) Time series of zonal wind stress anomalies averaged over the region $40^{\circ} \mathrm{W}-20^{\circ} \mathrm{W}, 3^{\circ} \mathrm{S}-$ $3^{\circ} \mathrm{N}$. (b) Positive maximum lagged correlation coefficients above 95\% significance level $(=0.08)$ and (c) corresponding lags between the wind time series shown in Figure 6a, the region is marked by the box, and the equatorial Atlantic SSH anomalies with a 1.6-m/s line superimposed along the equator. Anomalies are smoothed by a 10.5-day running mean. (d) Standard deviation of equatorial Atlantic SSH anomalies. 
(a) $35^{\circ} \mathrm{W}, 0^{\circ}$

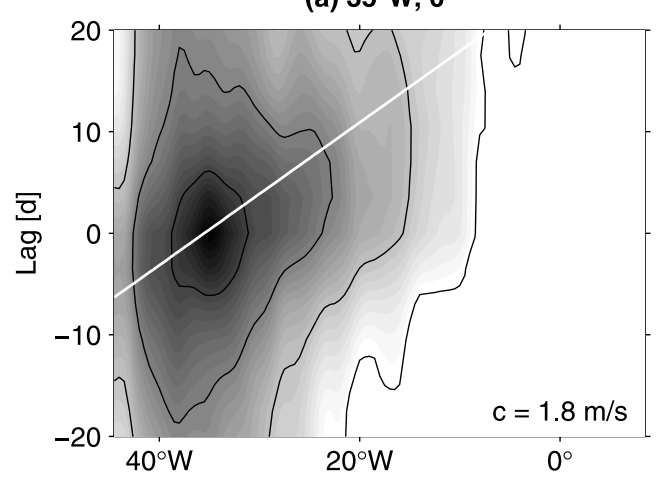

(b) $23^{\circ} \mathrm{W}, 0^{\circ}$

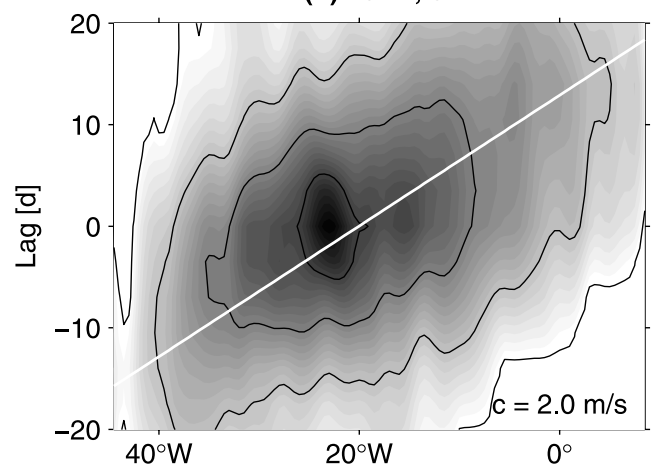

Correlation

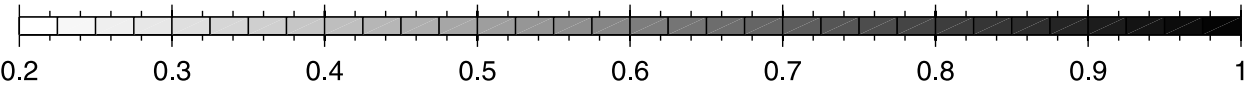

Figure 7. Lagged correlation of SSH anomalies along the equator with $\mathrm{SSH}$ anomalies at (a) $35^{\circ} \mathrm{W}, 0^{\circ}$ and (b) $23^{\circ} \mathrm{W}, 0^{\circ}$. The contour interval is 0.2 (black), and the white line corresponds to the estimated phase velocity as given in the lower right-hand corner (see text for details).

$\sum[\eta(y)-\mathrm{SSH}]^{2}$ for each longitude and time step, allowing only $\eta_{0}$ to vary. This fit accounts for up to $90 \%$ of the variance along the equator while explained variances decrease to about $60 \%$ at $3^{\circ}$ and $20 \%$ at $5^{\circ}$ in latitude, respectively (Figure 8). The structure function (equation (2)) that represents a mixture between first and second baroclinic mode waves is thus able to capture the dominant part of the equatorial Kelvin wave variability in the Atlantic.

\subsubsection{Equatorial Kelvin Wave Mode}

[33] The fitted SSH anomalies along the equator are then used to describe the equatorial Kelvin wave variability in terms of complex empirical orthogonal functions (CEOFs)

(a) Meridional Structure $[\mathrm{c}=1.9 \mathrm{~m} / \mathrm{s}]$

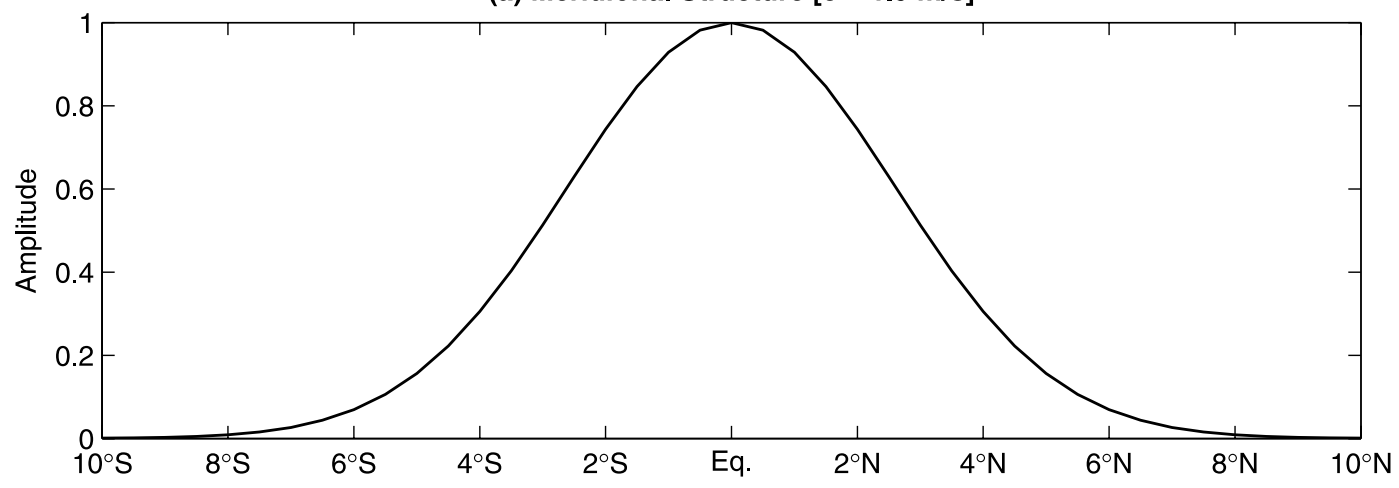

(b) Explained Variance

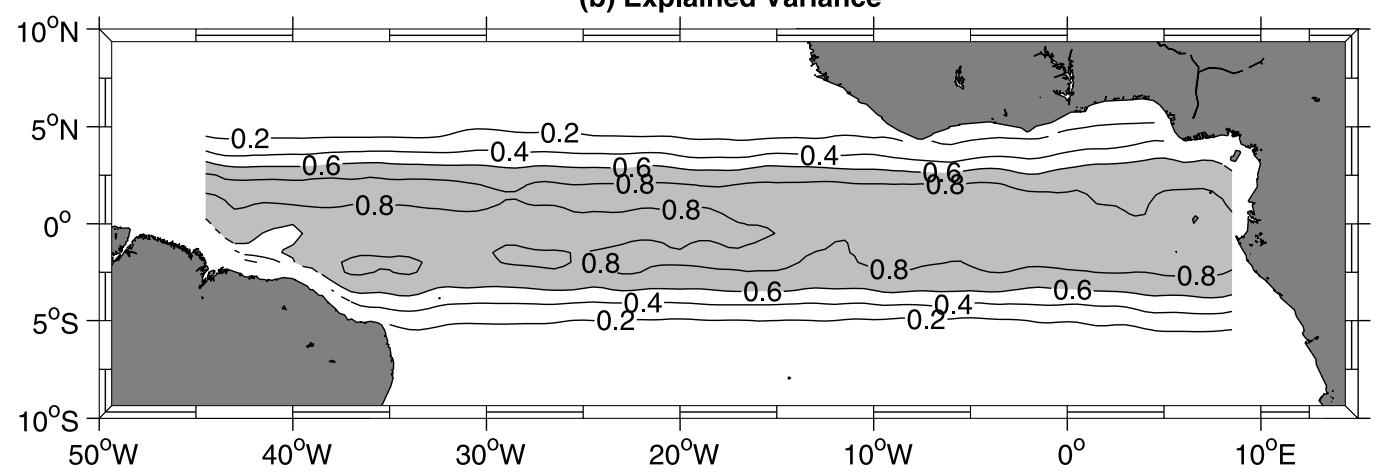

Figure 8. (a) Theoretical meridional structure of equatorial Kelvin waves according to equation (2), with $\eta_{0}=1$ and $c=1.9 \mathrm{~m} / \mathrm{s}$. (b) Explained variances corresponding to the least-square fit of SSH anomalies in the equatorial Atlantic to the theoretical meridional structure of equatorial Kelvin waves. 
1.CEOF: $50.1 \%$
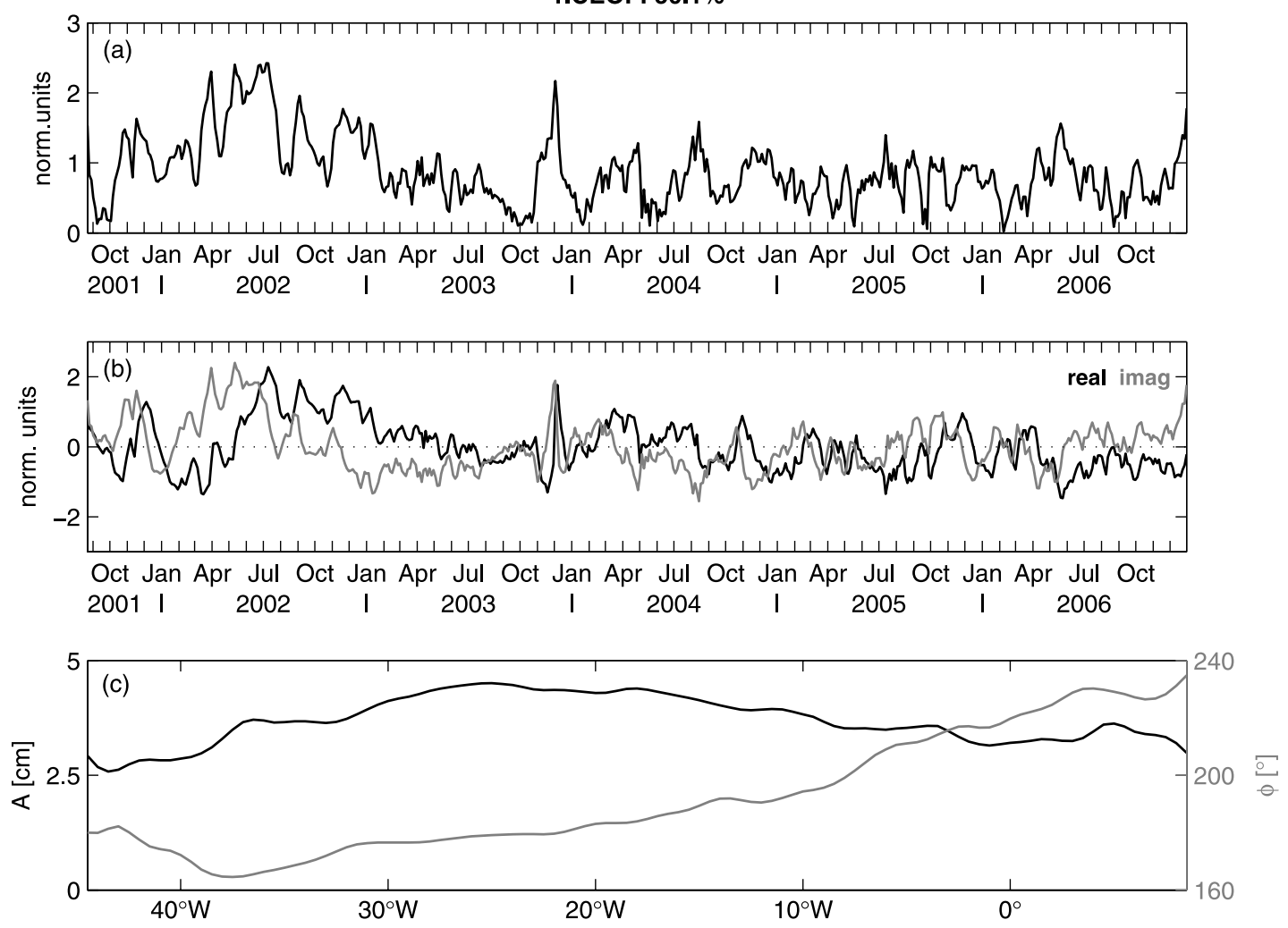

Figure 9. The 1. CEOF of fitted SSH anomalies along the equator: (a) temporal amplitude; (b) corresponding real (black) and imaginary (gray) components (normalized units), with the zero line dotted; and (c) spatial amplitude (cm; black) and relative phase (degree; gray).

[Barnett, 1983]. This technique is here more suitable than traditional EOF analysis because it is capable of detecting propagating features in space. Description of traveling features requires both co- and quadrature information that is provided in the time domain by a complex data set $D_{c}$ composed of a given real data set $D$ and its Hilbert transform, with the Hilbert transform (or quadrature function) representing $D$ phase shifted $\pi / 2$ in time. The zero lag covariance function of $D_{c}$ can then be used to investigate propagating features in $D$ and the EOF representation of $D_{c}$ is

$$
D_{c}(\mathbf{x}, t)=\sum \mathrm{A}_{\mathrm{n}}(t) B_{n}^{*}(\mathbf{x})
$$

with $\mathbf{x}$ representing coordinates in space, $t$ is time, $B_{n}^{*}(\mathbf{x})$ is the complex conjugation of the complex eigenvectors $B_{n}(\mathbf{x})$, and the (complex) time-dependent principal components $A_{\mathrm{n}}(t)$ are given by

$$
\mathrm{A}_{\mathrm{n}}(t)=\sum D_{c}(\mathbf{x}, t) B_{n}(\mathbf{x})
$$

Further details on this method are found in the work of Barnett [1983].

[34] The 1. CEOF explains $50.1 \%$ of the variance of the fitted SSH anomalies along the equator, with spatial amplitude maxima in the central part of the basin and relative phase increasing from west to east (Figure 9c). This spatial phase distribution clearly indicates an eastward propagation along the equator as consistent with the equatorial Kelvin waves. Considering the corresponding temporal amplitudes, equatorial Kelvin waves appear to be exceptionally strong during 2002 (Figures 9a and 9b). The variability during March to November 2002 is dominated by a spectral peak at about 60 days, while the weaker variability during March to November 2005 is associated with a spectral peak at about 40 days (not shown). Han et al. [2008] attributed the dominant spectral peak at 40-60 days during 2002/03 mainly to first and second baroclinic equatorial Kelvin wave modes.

[35] However, this mode shows a robust pattern of eastward propagating Kelvin waves along the equator and is adequate to describe their interannual variability in the equatorial region.

\subsection{Regression Analyses}

[36] The equatorial Kelvin wave mode, i.e., the complex 1. CEOF time series (see Figure 9b), is taken as a basis to analyze related oceanic variations with respect to the observed differences during 2002 and 2005. In order to do so, linear regression analyses are carried out with both satellite and moored observations; i.e., we apply linear regression models of the form

$$
\mathrm{Y}=\alpha \mathrm{X}=\left(\alpha_{\mathrm{r}}+\mathrm{i} \alpha_{\mathrm{i}}\right)\left(\mathrm{X}_{\mathrm{r}}+\mathrm{i} \mathrm{X}_{\mathrm{i}}\right)
$$

with $\mathrm{X}$ the complex CEOF time series (independent variable), $\mathrm{Y}$ the observed field (dependent variable), $\alpha$ regression coefficient, and subscripts denote real/imaginary component. 


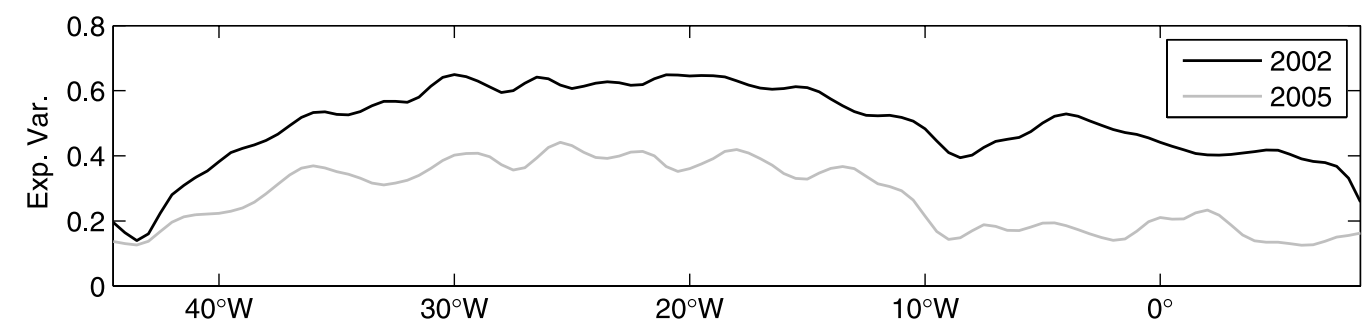

Figure 10. Explained variance of regressed SSH anomalies, with the complex 1. CEOF time series taken as a basis (see Figure 9b), during March to November 2002 (black) and 2005 (gray).

[37] At first, we regressed the original SSH anomalies for the period end-August 2001 to December 2006 onto the derived equatorial Kelvin wave mode to illustrate to which degree the $\mathrm{SSH}$ variability along the equator during March to November 2002 and 2005 can be attributed to this mode. The regression analysis accounts for about $60 \%$ and $40 \%$ of the variance in the central part of the basin during 2002 and 2005, respectively. Although somewhat lower values are also found in the eastern equatorial Atlantic during 2002, there is a substantial decrease to only about $15 \%$ of explained variance during 2005 (Figure 10). This strong reduction confirms our previous suggestion that dynamic processes, i.e., the eastward propagation of equatorial Kelvin waves, might be of minor importance in the cold tongue region itself during boreal summer 2005. Even though the SSHs can mainly be attributed to dynamical effects, thermal energy anomalies can contribute as well [Gill and Niiler, 1973; Chambers et al., 1997]. The thermocline was exceptionally shallow in the eastern equatorial Atlantic during boreal summer 2005 [Marin et al., 2009, Figure 4a] and hence subsurface ocean processes were more tightly coupled to surface processes. As pointed out by Marin et al. [2009], intraseasonal intensifications of the southeast trades in the Gulf of Guinea are mostly able to enhance local mixing at the base of the mixed layer to induce extra SST cooling with such a mechanism more efficient when the mixed layer is shallow. This may be, at least in parts, a reason that only a small part of the $\mathrm{SSH}$ variance in the eastern basin during 2005 could be explained by the equatorial Kelvin wave mode.

[38] However, the absolute regression pattern of SST anomalies for the period end-August 2001 to December 2006 reveals generally largest coefficients in the central equatorial Atlantic; with another maximum in the eastern near-coastal regions south of the equator (Figure 11a). As shown by Polo et al. [2008] and also indicated by the relative phases from the SST regression analysis (not shown), signals associated with equatorial Kelvin waves can propagate further along the African coast and can consequently contribute to the SST variability in the coastal upwelling regions. This continuing propagation as coastal Kelvin waves from the equator northward and southward along the African coast is studied in detail by Polo et al. [2008].

[39] The corresponding regressed March to November time series of cold tongue SST anomalies during 2002 and 2005 (Figure 11b) show that the direct influence of equatorial Kelvin waves is small compared to the actual SST variability in this region (see Figures $4 \mathrm{c}$ and $4 \mathrm{f}$ ). However, note that the observed evolution of cold tongue SST anomalies is generally captured by the regressed time series during 2002, while in particular the strong cooling during May/June 2005 is not reproduced (Figure 4f).

[40] In order to point toward possible causes for the observed differences during 2002 and 2005, a regression of equatorial thermocline slope anomalies onto the equatorial Kelvin wave mode is performed. The thermocline slope is here computed as the difference between the moored $20^{\circ} \mathrm{C}$ isotherm depths at $35^{\circ} \mathrm{W}$ and $23^{\circ} \mathrm{W}$ divided by the distance, with positive slope anomalies indicating an increased eastward thermocline rise compared to the mean state. In consequence of an anomalously steep slope, the thermocline will be closer to the surface in the east but deeper in the west.

[41] The regressed March to November time series show negative thermocline slope anomalies from March to June 2002 and positive thermocline slope anomalies afterwards. During 2005, the thermocline slope is increased (reduced) prior to (after) July 2005 (Figure 11c). The regressed SST anomalies in the cold tongue region are positive (negative) in correspondence with reduced (increased) thermocline slopes.

[42] Our findings concerning the regressed thermocline slope anomalies are in agreement with the time series of anomalous SSH in the eastern equatorial Atlantic presented by Grodsky et al. [2008, Figure 3a]: During the first half year of 2002 (2005), positive (negative) anomalies prevailed while largely negative (positive) ones were found during the second half year; with positive (negative) values corresponding to a deepening (shallowing) of the thermocline in the east.

[43] While the direct influence of equatorial Kelvin waves on SST variability in the cold tongue region is rather small, the flattened (steeper) thermocline slope covarying with the equatorial Kelvin wave mode prior to the cold tongue onset in 2002 (2005) appears to be favorable for the development of the warm (cold) event. During boreal spring 2002, the imaginary temporal component of the equatorial Kelvin wave mode prevails (see Figure 9b) and the corresponding regression pattern of the wind stress anomalies in the equatorial Atlantic indicates a relaxation of the equatorial easterly winds in the western to central part of the basin (Figure 12b). In response, the equatorial thermocline will shoal in the west and the basin-wide adjustment of the thermocline slope by downwelling equatorial Kelvin waves will then result in a deeper thermocline in the east. While this zonal wind mechanism is also in agreement with the observed anomalous wind field during 2002, the mechanism seems to be different during 2005 where largest wind anomalies were more shifted toward the western boundary.

[44] Considering now the zonal velocity anomalies at $23^{\circ} \mathrm{W}, 0^{\circ}$ covarying with the equatorial Kelvin wave mode both the overall regression amplitude and corresponding 



Figure 11. (a) Absolute regression pattern of SST anomalies $\left({ }^{\circ} \mathrm{C}\right)$ in the equatorial Atlantic onto the complex 1. CEOF time series (see Figure 9b), with the cold tongue box marked by dashed lines and the mooring locations indicated by white crosses. (b) Regressed cold tongue SST anomalies and (c) regressed equatorial thermocline slope anomalies, with positive values indicating an increased eastward thermocline rise (see text for details), from March to November 2002 (black) and 2005 (gray).


Figure 12. (a) Real and (b) imaginary regression patterns of zonal and meridional wind stress anomalies $\left(\mathrm{N} / \mathrm{m}^{2}\right.$; scale indicated) in the equatorial Atlantic onto the complex 1. CEOF time series (see Figure $9 \mathrm{~b}$ ). 

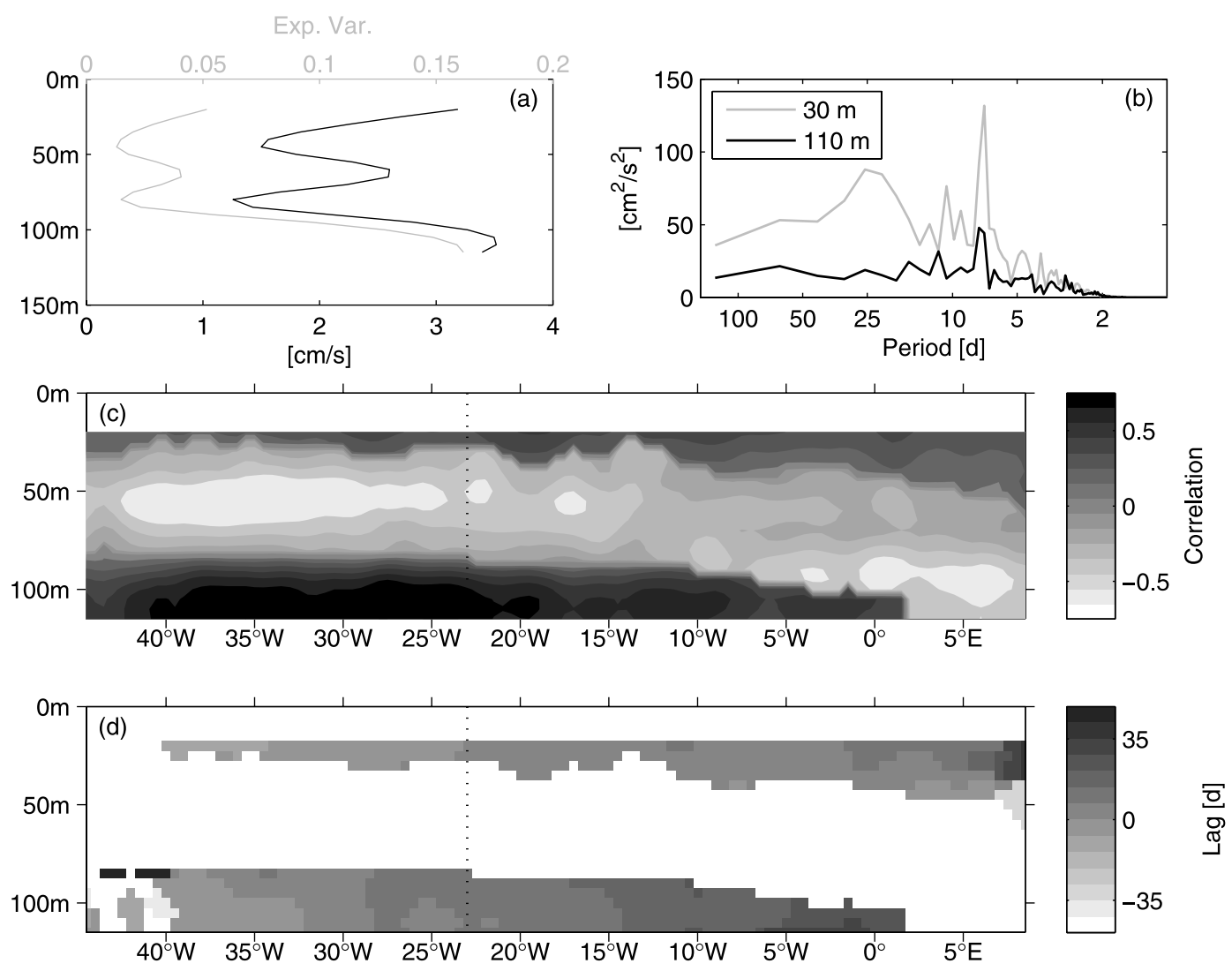

Figure 13. (a) Regression amplitude (black; $\mathrm{cm} / \mathrm{s}$ ) and corresponding explained variance (gray) of equatorial zonal velocity anomalies at $23^{\circ} \mathrm{W}$ onto the complex 1 . CEOF time series (see Figure $9 \mathrm{~b}$ ). (b) Combined variance-conserving power spectra of 30-m (gray) and $110-\mathrm{m}$ (black) zonal velocities at $23^{\circ} \mathrm{W}, 0^{\circ}\left(\mathrm{cm}^{2} / \mathrm{s}^{2}\right)$ for the first and third deployment periods. (c) Maximum lagged correlation coefficients and (d) corresponding lags between zonal velocity anomalies at $23^{\circ} \mathrm{W}, 0^{\circ}$ and $\mathrm{SSH}$ anomalies along the equator. Lags are only shown for positive correlation coefficients above $95 \%$ significance level $(=0.14)$, and anomalies are smoothed by a 10.5-day running mean for the correlation analysis; mooring position is marked by a dotted line.

explained variance are largest at $110-\mathrm{m}$ depth with a secondary maximum near the surface (Figure 13a). Figure 13b presents variance-conserving power spectra of $30-\mathrm{m}$ and $110-\mathrm{m}$ zonal velocities at $23^{\circ} \mathrm{W}, 0^{\circ}$ and generally higher power is found for the near-surface current. Besides the strong spectral peaks in 30-m zonal velocities at periods of about 7 and 25 days that are extensively discussed by e.g., Grodsky et al. [2005] and Bunge et al. [2007] for the first current meter mooring deployment period during 2002 and the latter one related to tropical instability waves, enhanced power is also observable at a period of about 60 days. This 60 -day variability is as well present in the $110-\mathrm{m}$ zonal velocities, here of equal magnitude as the 25-day peak. As noted above, Han et al. [2008] attributed the dominant spectral peak at 40-60 days during 2002/03 mainly to first and second baroclinic Kelvin wave modes.

[45] In order to further illustrate the effect of equatorial Kelvin waves on $23^{\circ} \mathrm{W}$ - zonal velocity anomalies at the equator, a lagged correlation analysis is performed with respect to SSH anomalies along the equator (Figures 13c and 13d). Both the shallow and deep maximum of the regression analysis (Figure 13a) are here well reproduced and maximum correlation coefficients at around $110-\mathrm{m}$ depth are up to twice as much as near the surface. Note the negative values in between these maxima, with a minimum at about $50-\mathrm{m}$ depth near the western boundary. In case of the near-surface currents largest correlation coefficients are confined to the central and eastern equator whereas maximum values are found at the western and central equator as regards the currents around $110-\mathrm{m}$ depth. Although there are also indications for an eastward propagation along the equator in case of the near-surface currents, such a propagation is more pronounced in the depth range of the deep regression maximum. For the 110-m zonal velocity anomalies, the corresponding phase velocity can be estimated to about $1.8 \mathrm{~m} / \mathrm{s}$ which again fits well in the range between the first and second baroclinic equatorial Kelvin wave modes (see Table 2).

[46] While the high correlation coefficients at the central and eastern equator can be related to zonal wind variations in the western and central equatorial Atlantic, such fluctuations might not be responsible for the large values in the west as obtained for the depth range of the deep regression maximum (see Figure $6 \mathrm{~b}$ ). In this context, wave reflection processes at the western boundary may be of importance, but we were not able to establish such a mechanism using the available data. Illig et al. [2004] suggested that the presence of a strong western boundary current, the NBC, may 
modify/inhibit reflections of westward propagating Rossby waves into equatorial Kelvin waves.

[47] For low baroclinic modes, near-surface positive correlation coefficients are associated with Kelvin waves and negative correlation coefficients with Rossby waves. The observed negative correlation coefficients in between regions of positive correlation coefficients near the surface and below the EUC core (Figure 13c) might be related to equatorial Rossby waves [e.g., Moore and Philander, 1977], but a corresponding westward propagation could not be evidenced here.

\section{Summary and Discussion}

[48] In this study, the upper equatorial Atlantic variability during 2002 and 2005 was analyzed with respect to equatorial Kelvin waves on the basis of both moored and satellite observations.

[49] The inspection of the interannual boreal summer cold tongue variability revealed a warm event during 2002 and a strong cold event during 2005 in conjunction with reduced and enhanced easterlies to the west, respectively. According to its dynamics, the EUC was observed to be embedded in a shallower (deeper) thermocline during boreal summer 2002 (2005) at $23^{\circ} \mathrm{W}, 0^{\circ}$. However, while model studies also indicate an overall weakening (increasing) of the upper ocean equatorial circulation during warm (cold) events [Góes and Wainer, 2003; Hormann and Brandt, 2007], the EUC core velocity was here observed to be somewhat stronger in 2002 than 2005. Weisberg et al. [1987] analyzed moored observations at $28^{\circ} \mathrm{W}, 0^{\circ}$ from February 1983 to October 1985 (i.e., covering the warm event during 1984) and noted that the speed at the EUC core remained relatively steady throughout the year.

[50] However, it was shown that anomalous winds in the west can excite Kelvin waves along the equator and former studies suggested a remote forcing of SST anomalies in the eastern equatorial Atlantic via these waves [e.g., Moore et al., 1978; Servain et al., 1982; McCreary et al., 1984]. During both 2002 and 2005, equatorial Kelvin waves were found to be present in moored observations as $20^{\circ} \mathrm{C}$ isotherm depth anomalies and dynamic height anomalies at $35^{\circ} \mathrm{W}, 0^{\circ}$ and $23^{\circ} \mathrm{W}, 0^{\circ}$. Their phase velocity was basically estimated to be about $1.4 \mathrm{~m} / \mathrm{s}$ eastward which is in good agreement with the theoretical value of the second baroclinic equatorial Kelvin wave mode (see Tables 1 and 2).

[51] Eastward propagations along the equator were also prominent in the basin-wide SSH anomalies, with an overall phase velocity between $1.8-2.0 \mathrm{~m} / \mathrm{s}$. This somewhat higher estimate for the whole period from end-August 2001 to December 2006 fits well in the range between the first and second baroclinic mode of equatorial Kelvin waves. As noted above, the SSH is most sensitive to the first baroclinic mode while the vertical displacement in the depth range of the $20^{\circ} \mathrm{C}$ isotherm is more sensitive to the second (compared to the first) baroclinic mode. However, the second baroclinic mode was found to be the most energetic in the model study by Illig et al. [2004] and Han et al. [2008] also suggested a more important role of this mode.

[52] The SSH variability was then described in terms of an equatorial Kelvin wave mode by first performing a leastsquare fit to the theoretical meridional Kelvin wave struc- ture that was in turn subject to a CEOF analysis. This mode accounted for $50.1 \%$ of the variance along the equator and captured well the characteristics of equatorial Kelvin waves, with wave activity exceptionally strong during 2002.

[53] On the basis of the equatorial Kelvin wave mode, regression analyses were carried out to derive related oceanic variations with respect to the observed differences during 2002 and 2005. Compared to the exceptionally strong wave activity in 2002, equatorial Kelvin waves were generally weaker during 2005. While a large part of the SSH variability in both the central and eastern equatorial Atlantic was captured by the regression analysis during 2002, this was different during 2005: In the central part of the basin, about $40 \%$ of the $\mathrm{SSH}$ variance could be explained but only about $15 \%$ in the east. In addition, the observed evolution of cold tongue SST anomalies was basically reproduced by the regressed time series during 2002 but the strong cooling during 2005 was not.

[54] While the direct influence of equatorial Kelvin waves on SST was found to be generally small, preconditioning of the upper layer stratification before the onset of the cold tongue may be important for its strength during boreal summer. The examination of the regressed equatorial thermocline slope anomalies during 2002 and 2005 revealed that an anomalously reduced (increased) thermocline slope may be favorable for the development of the warm (cold) event. Because of the shallow thermocline in the east, even small changes in thermocline slope may here be of primary importance; particularly with respect to the coupling between surface and subsurface ocean processes.

[55] Prior to the warm event in 2002, equatorial easterly winds in the western to central Atlantic covarying with the equatorial Kelvin wave mode were relaxed. In response, the thermocline shoaled in the west and the basin-wide adjustment of the equatorial thermocline slope by downwelling Kelvin waves then resulted in a deeper thermocline in the east. Otherwise, such a zonal wind mechanism could not be established for the strong cold event in 2005. An inspection of the 2. CEOF of fitted SSH anomalies (see equation (2)), which explains $27.5 \%$ of the variance along the equator, reveals large amplitudes during 2005. It is associated with an east-west seesaw pattern that represents an out-of-phase oscillation of SSH (and thermocline) between East and West Atlantic (Figure 14). Such a spatial pattern may be attributed to the linear response of the equatorial ocean to periodic and symmetric forcing as described by Cane and Sarachik [1981] and extended toward a more arbitrary distribution of easterly wind stress by Weisberg and Tang [1990]. The corresponding real and imaginary regression patterns of the wind stress anomalies in the equatorial Atlantic (Figure 15) indicate a relaxation (intensification) of the southeast (northeast) trades during boreal winter/ spring 2005 (negative imaginary regression pattern) and a strong intensification (relaxation) of the southeast (northeast) trades during boreal summer starting in mid-April (negative real regression pattern). The anomalous behavior in the tropical Atlantic during 2005, also characterized by a record-breaking hurricane season, can be explained by the presence of a meridional mode that developed in boreal spring with anomalously cold SSTs in the south and anomalously warm SSTs in the north (see Figure 2d). Associated with this meridional SST gradient was a north- 
2.CEOF: $27.5 \%$
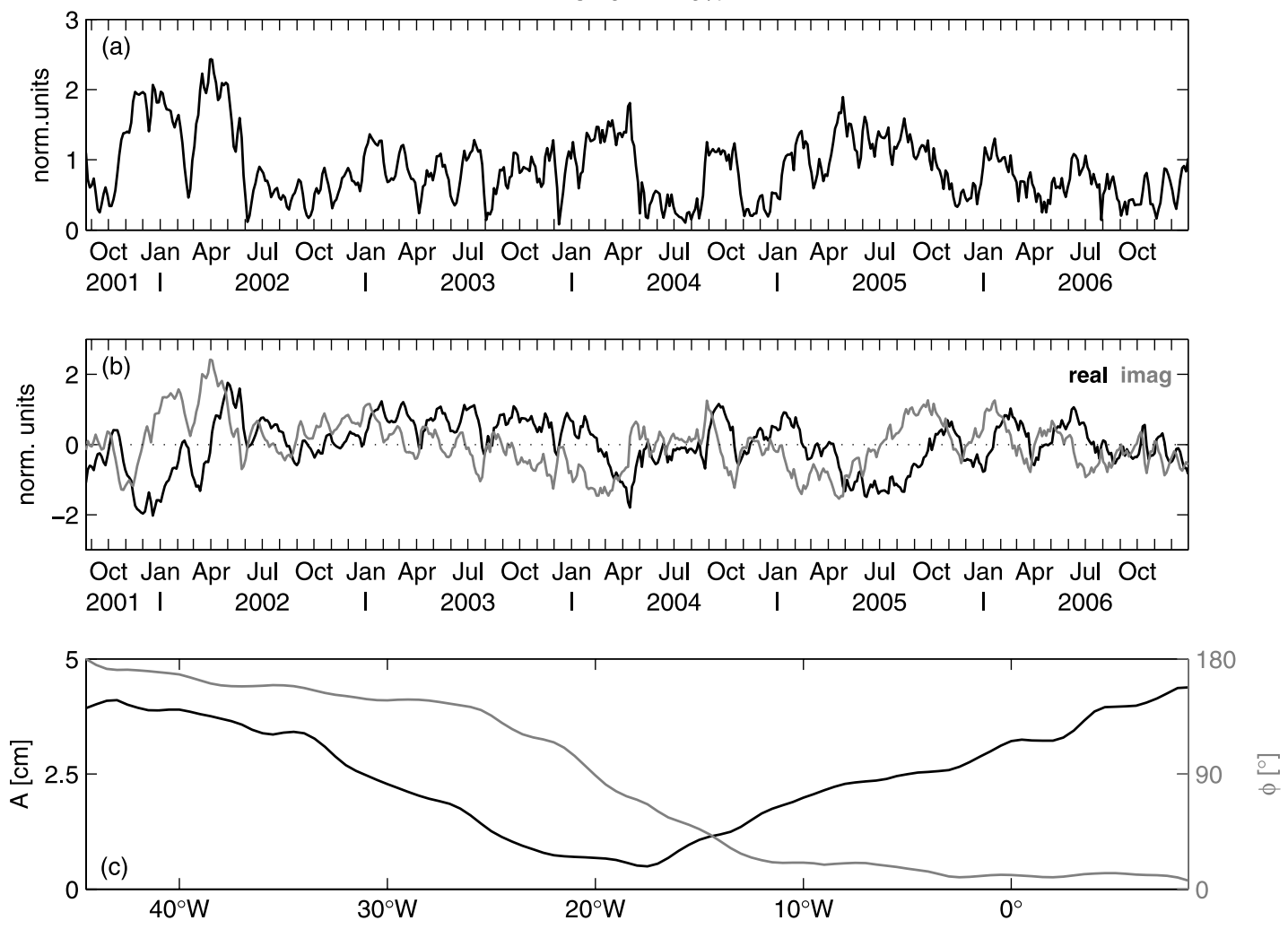

Figure 14. Same as Figure 9, but for the 2. CEOF.

ward shift of the intertropical convergence zone by about $2^{\circ}$ in latitude from mid-April to mid-September corresponding to the observed wind intensification in the west [Foltz and McPhaden, 2006; Janicot et al., 2008].

[56] Anomalous thermocline slopes prior to Atlantic extreme events are generally well established and ocean dynamics are known to play a prominent role in their generation [e.g., Philander, 1986; Weisberg and Tang, 1987; Carton and Huang, 1994; Carton et al., 1996; Vauclair and $d u$ Penhoat, 2001]. For instance, the anomalous deepening of the oceanic thermocline in the eastern basin prior to the warm event in 1984 that was proceeded by weaker-than-normal trade winds [Philander, 1986] resulted from an eastward shift of anomalous heat within the equatorial waveguide [Carton and Huang, 1994]. Because of relaxed (intensified) winds in the west, the thermocline there shoals (deepens) and excited equatorial Kelvin waves are believed to be important for the subsequent adjustment of the thermocline slope along the equator [e.g., Moore et al., 1978; McCreary et al., 1984; Zebiak, 1993]. In addition, linear equatorial wave reflection theory indicates that an eastward propagating Kelvin wave impinging on a meridional east coast would be reflected into symmetrical westward propagating Rossby waves and coastal Kelvin waves [Moore and Philander, 1977]; leading to an extended response throughout the eastern basin.

[57] The reversal of the regressed equatorial thermocline slope anomalies during boreal summer (see Figure 11c) also indicates a possible contribution of equatorial Kelvin waves to the oceanic readjustment after the extreme events, with prevailing upwelling (downwelling) Kelvin waves along the equator after the warm (cold) event in 2002 (2005). Otherwise, the simple model study by Zebiak [1993] suggested that the dominant processes contributing to the decay of the SST in the eastern equatorial Atlantic are horizontal advection, particularly the meridional component, and the damping effect of the surface heat fluxes.

[58] The zonal velocity anomalies at $23^{\circ} \mathrm{W}, 0^{\circ}$ were also found to covary with the equatorial Kelvin wave mode and the main effect of these waves was evident well below the EUC core at 110-m depth, with an additionally shallow maximum near the surface. Johnson and McPhaden [1993a] studied the vertical structure of equatorial Kelvin waves in the Pacific using frequency-domain EOFs. Besides an amplitude maximum at the surface, the spatial zonal velocity patterns revealed a local amplitude maximum below the EUC core attributed to wave - mean flow interactions. In a follow-up study, Johnson and McPhaden [1993b] identified mean vertical advection as the most important effect in modifying linear equatorial Kelvin wave propagations. A subsurface amplitude maximum in zonal velocity below the EUC core was also found by Kutsuwada and McPhaden [2002] investigating intraseasonal variations in the upper equatorial Pacific prior to and during the 1997-98 El Niño.

[59] As a key result of this study, the presence of equatorial Kelvin waves is associated with a flattened (steeper) thermocline slope prior to the cold tongue onset in 2002 (2005) that is crucial for the shallowing (deepening) of the EUC core at $23^{\circ} \mathrm{W}$ and that might precondition the development of the warm (cold) event. Preconditioning of the upper layer stratification may also be important for a predictability of Atlantic 

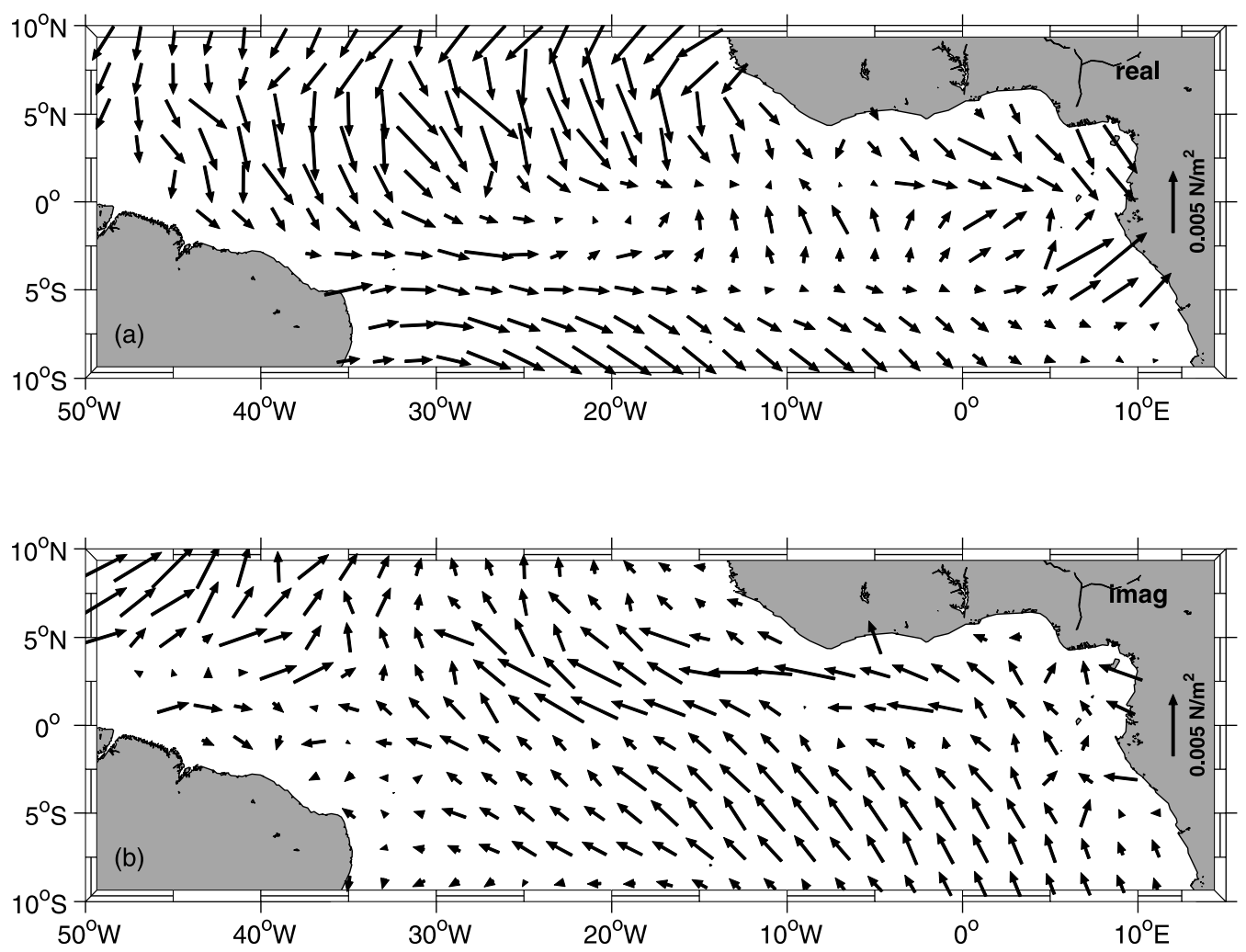

Figure 15. Same as Figure 12, but for the 2. CEOF.

extreme events that are closely linked with rainfall variability over the tropical ocean and adjacent land regions [e.g., Carton and Huang, 1994; Giannini et al., 2003; Kushnir et al., 2006; Chang et al., 2006].

[60] Acknowledgments. For helpful discussions, we would like to thank F. Marin and N. Keenlyside. We are also grateful to C. Provost and B. Bourlès for providing moored ADCP data, as well as to R. Lumpkin and C. Schmid for allocating data from two $R V$ Ron Brown cruises. As regards the PIRATA data, we acknowledge the effort of the TAO project office. The altimeter data were produced by SSALTO/DUACS and distributed by AVISO with support from CNES. Surface wind stress data were obtained from CERSAT, at IFREMER, Plouzané (France). Microwave OI SST data were produced by Remote Sensing Systems and sponsored by the National Oceanographic Partnership Program (NOPP), the NASA Earth Science Physical Oceanography Program, and the NASA REASoN DISCOVER Project. This study was funded by the Deutsche Bundesministerium für Bildung und Forschung (BMBF) as part of the Verbundvorhaben Nordatlantik (03F0443B), the German Science Foundation (DFG) under contracts FI 871/1-1 and BR 2286/1-1, as well as the EU Integrated Project AMMA (004089-2).

\section{References}

Arnault, S., A. Morlière, J. Merle, and Y. Ménard (1992), Low-frequency variability of the tropical Atlantic surface topography: Altimetry and model comparison, J. Geophys. Res., 97(C9), 14,259-14,288.

Barnett, T. P. (1983), Interaction of the monsoon and Pacific trade wind system at interannual time scales. part I: The equatorial zone, Mon. Weather Rev., 111, 756-773.

Bjerknes, J. (1969), Atmospheric teleconnections from the equatorial Pacific, Mon. Weather Rev., 97, 163-172.

Brandt, P., F. A. Schott, C. Provost, A. Kartavtseff, V. Hormann, B. Bourlès, and J. Fischer (2006), Circulation in the central equatorial Atlantic: Mean and intraseasonal to seasonal variability, Geophys. Res. Lett., 33, L07609, doi:10.1029/2005GL025498.

Brandt, P., V. Hormann, B. Bourlès, J. Fischer, F. A. Schott, L. Stramma, and M. Dengler (2008), Oxygen tongues and zonal currents in the equatorial Atlantic, J. Geophys. Res., 113, C04012, doi:10.1029/ 2007JC004435.
Bunge, L., C. Provost, and A. Kartavtseff (2007), Variability in horizontal current velocities in the central and eastern equatorial Atlantic in 2002, J. Geophys. Res., 112, C02014, doi:10.1029/2006JC003704.

Cane, M. A., and E. S. Sarachik (1976), Forced baroclinic ocean motions. part I: The linear equatorial unbounded case, J. Mar. Res., 34, 629-666. Cane, M. A., and E. S. Sarachik (1977), Forced baroclinic ocean motions. part II: The linear equatorial bounded case, J. Mar. Res., 35, 395-432.

Cane, M. A., and E. S. Sarachik (1981), The response of a linear baroclinic equatorial ocean to periodic forcing, J. Mar. Res., 39, 651-693.

Carton, J. A., and B. Huang (1994), Warm events in the tropical Atlantic, J. Phys. Oceanogr., 24, 888-903.

Carton, J. A., X. Cao, B. S. Giese, and A. M. Da Silva (1996), Decadal and interannual SST variability in the tropical Atlantic Ocean, J. Phys. Oceanogr., 26, 1165-1175.

Chambers, D., B. Tapley, and R. Stewart (1997), Long-period ocean heat storage rates and basin-scale heat fluxes from TOPEX, J. Geophys. Res., 102(C5), 10,525-10,533.

Chang, P., et al. (2006), Climate fluctuations of tropical coupled systemsThe role of ocean dynamics, J. Clim., 19, 5122-5174.

Delcroix, T., J. Picaut, and G. Eldin (1991), Equatorial Kelvin and Rossby waves evidenced in the Pacific Ocean through Geosat sea level and surface current anomalies, J. Geophys. Res., 96(Suppl.), 3249-3262.

Firing, E., R. Lukas, J. Sadler, and K. Wyrtki (1983), Equatorial Undercurrent disappears during 1982-1983 El Niño, Science, 222, 1121-1123.

Foltz, G. R., and M. J. McPhaden (2006), Unusually warm sea surface temperatures in the tropical North Atlantic during 2005, Geophys. Res. Lett., 33, L19703, doi:10.1029/2006GL027394.

França, C., I. Wainer, A. R. de Mesquita, and G. J. Goni (2003), Planetary equatorial trapped waves in the Atlantic Ocean from TOPEX/POSEIDON altimetry, in Interhemispheric Water Exchange in the Atlantic Ocean, Elsevier Oceanogr. Ser., vol. 68, edited by G. J. Goni and P. MalanotteRizzoli, pp. 213-232, Elsevier, New York.

Giannini, A., R. Saravanan, and P. Chang (2003), Oceanic forcing of Sahel rainfall on interannual to interdecadal time scales, Science, 302, $1027-1030$

Giarolla, E., P. Nobre, M. Malagutti, and P. Pezzi (2005), The Atlantic Equatorial Undercurrent: PIRATA observations and simulations with GFDL Modular Ocean model at CPTEC, Geophys. Res. Lett., 32, L10617, doi:10.1029/2004GL022206.

Gill, A. E., and P. P. Niiler (1973), The theory of the seasonal variability in the ocean, Deep Sea Res., 20, 141-177. 
Góes, M., and I. Wainer (2003), Equatorial currents transport changes for extreme warm and cold events in the Atlantic Ocean, Geophys. Res. Lett. 30(5), 8006, doi:10.1029/2002GL015707.

Grodsky, S. A., J. A. Carton, C. Provost, J. Servain, J. A. Lorenzzetti, and M. J. McPhaden (2005), Tropical instability waves at $0^{\circ} \mathrm{N}, 23^{\circ} \mathrm{W}$ in the Atlantic: A case study using Pilot Research Moored Array in the Tropical Atlantic (PIRATA) mooring data, J. Geophys. Res., 110, C08010, doi:10.1029/2005JC002941.

Grodsky, S. A., J. A. Carton, and C. R. McClain (2008), Variability of upwelling and chlorophyll in the equatorial Atlantic, Geophys. Res. Lett., 35, L03610, doi:10.1029/2007GL032466.

Han, W., P. J. Webster, J.-L. Lin, W. T. Liu, R. Fu, D. Yuan, and A. Hu (2008), Dynamics of intraseasonal sea level and thermocline variability in the equatorial Atlantic during 2002-03, J. Phys. Oceanogr., 38(5), 945-967, doi:10.1175/2008JPO3854.1.

Hisard, P., and C. Hénin (1987), Response of the equatorial Atlantic Ocean to the 1983-1984 wind from the Programme Français Océan et Climat dans l'Atlantique Equatorial cruise data set, J. Geophys. Res., 92(C4), 3759-3768.

Hisard, P., C. Hénin, R. Houghton, B. Piton, and P. Rual (1986), Oceanic conditions in the tropical Atlantic Ocean during 1983 and 1984, Nature, $322,243-245$.

Hormann, V., and P. Brandt (2007), Atlantic Equatorial Undercurrent and associated cold tongue variability, J. Geophys. Res., 112, C06017, doi:10.1029/2006JC003931

Illig, S., B. Dewitte, N. Ayoub, Y. du Penhoat, G. Reverdin, P. De Mey, F. Bonjean, and G. S. E. Lagerloef (2004), Interannual long equatoria waves in the tropical Atlantic from a high-resolution ocean general circulation model experiment in 1981-2000, J. Geophys. Res., 109, C02022, doi:10.1029/2003JC001771.

Janicot, S., et al. (2008), Large-scale overview of the summer monsoon over West Africa during the AMMA field experiment in 2006, Ann. Geophys., 26, 2569-2595.

Johnson, E. S., and M. J. McPhaden (1993a), Structure of intraseasonal Kelvin waves in the equatorial Pacific Ocean, J. Phys. Oceanogr., 23, $608-625$

Johnson, E. S., and M. J. McPhaden (1993b), Effects of a three-dimensional mean flow on intraseasonal Kelvin waves in the equatorial Pacific Ocean, J. Geophys. Res., 98(C6), 10,185-10,194.

Johnson, G. C., B. M. Sloyan, W. S. Kessler, and K. E. McTaggart (2002), Direct measurements of upper ocean currents and water properties across the tropical Pacific during the 1990s, Prog. Oceanogr., 52, 31-61, doi:10.1016/S0079-6611(02)00021-6.

Katz, E. J. (1987), Equatorial Kelvin waves in the Atlantic, J. Geophys. Res., 92(C2), 1894-1898

Katz, E. J. (1997), Waves along the equator in the Atlantic, J. Phys. Oceanogr., 27, 2536-2544.

Katz, E. J., P. Hisard, J. M. Verstraete, and S. Garzoli (1986), Annua change of sea surface slope along the equator of the Atlantic Ocean in 1983 and 1984, Nature, 222, 245-247.

Keenlyside, N. S., and M. Latif (2007), Understanding equatorial Atlantic interannual variability, J. Clim., 20(1), 131-142.

Kushnir, Y., W. A. Robinson, P. Chang, and A. W. Robertson (2006), The physical basis for predicting Atlantic sector seasonal-to-interannual climate variability, J. Clim., 19, 5949-5970.

Kutsuwada, K., and M. J. McPhaden (2002), Intraseasonal variations in the upper equatorial Pacific Ocean prior to and during the 1997-98 El Niño, J. Phys. Oceanogr., 32, 1133-1149.

Latif, M., and A. Grötzner (2000), The equatorial Atlantic oscillation and its response to ENSO, Clim. Dyn., 16, 213-218.

Marin, F., G. Caniaux, B. Bourlès, H. Giordani, Y. Gouriou, and E. Key (2009), Why were sea surface temperatures so different in the eastern equatorial Atlantic in June 2005 and 2006?, J. Phys. Oceanogr., doi:10.1175/2008JPO4030.1, in press.

Matsuno, T. (1966), Quasi-geostrophic motions in the equatorial area, J. Meteorol. Soc. Jpn., 44, 25-43.

McCreary, J. P., J. Picaut, and D. Moore (1984), Effects of remote annua forcing in the eastern tropical Atlantic Ocean, J. Mar. Res., 42, 45-81.

Merle, J. M., M. Fieux, and P. Hisard (1980), Annual signal and interannual anomalies of sea surface temperatures in the eastern equatorial Atlantic Ocean, Deep Sea Res., 26, Suppl. II-V, 77-102.

Moore, D., and S. G. H. Philander (1977), Modeling of the tropical oceanic circulation, in The Sea, vol. 6, edited by E. D. Goldberg et al., pp. 319361, Wiley-Interscience, Hoboken, N. J.
Moore, D. W., P. Hisard, J. P. McCreary, J. Merle, J. J. O’Brien, J. Picaut, J.-M. Verstraete, and C. Wunsch (1978), Equatorial adjustment in the eastern Atlantic, Geophys. Res. Lett., 5(8), 637-640.

Philander, S. G. H. (1986), Unusual conditions in the tropical Atlantic Ocean in 1984, Nature, 222, 236-238.

Philander, S. G. H., and R. C. Pacanowski (1986), A model of the seasonal cycle in the tropical Atlantic Ocean, J. Geophys. Res., 91(C12), 14,192-14,206.

Polo, I., A. Lazar, B. Rodriguez-Fonseca, and S. Arnault (2008), Oceanic Kelvin waves and tropical Atlantic intraseasonal variability: 1. Kelvin wave characterization, J. Geophys. Res., 113, C07009, doi:10.1029/ 2007JC004495.

Provost, C., S. Arnault, N. Chouaib, A. Kartavtseff, L. Bunge, and E. Sultan (2004), TOPEX/Poseidon and Jason equatorial sea surface slope anomaly in the Atlantic in 2002: Comparison with wind and current measurements at 23W, Mar. Geod., 27, 31-45.

Rebert, J. P., J. R. Donguy, G. Eldin, and K. Wyrtki (1985), Relations between sea level, thermocline depth, heat content, and dynamic height in the tropical Pacific Ocean, J. Geophys. Res., 90(C6), 11,719-11,725.

Reynolds, R. W., and T. M. Smith (1994), Improved global sea surface temperature analysis using optimum interpolation, J. Clim., 7, 929-948.

Schouten, M. W., R. P. Matano, and T. P. Strub (2005), A description of the seasonal cycle of the equatorial Atlantic from altimeter data, Deep Sea Res. Part I, 52, 477-493.

Seidel, H. F., and B. S. Giese (1999), Equatorial currents in the Pacific Ocean 1992-1997, J. Geophys. Res., 104(C4), 7849-7863.

Servain, J., J. Picaut, and J. Merle (1982), Evidence of remote forcing in the equatorial Atlantic Ocean, J. Phys. Oceanogr., 12, 457-463.

Servain, J., A. J. Busalacchi, M. J. McPhaden, A. D. Moura, G. Reverdin M. Vianna, and S. E. Zebiak (1998), A Pilot Research Moored Array in the Tropical Atlantic (PIRATA), Bull. Am. Meteorol. Soc., 79, 2019-2031.

Servain, J., I. Wainer, J. P. McCreary, and A. Dessier (1999), Relationship between the equatorial and meridional modes of climatic variability in the tropical Atlantic, Geophys. Res. Lett., 26(4), 485-488.

Vauclair, F., and Y. du Penhoat (2001), Interannual variability of the upper layer of the tropical Atlantic Ocean from in situ data between 1979 and 1999, Clim. Dyn., 17, 527-546.

von Schuckmann, K., P. Brandt, and C. Eden (2008), Generation of tropical instability waves in the Atlantic Ocean, J. Geophys. Res., 113, C08034, doi:10.1029/2007JC004712.

Wacongne, S. (1989), Dynamical regimes of a fully nonlinear stratified model of the Atlantic Equatorial Undercurrent, J. Geophys. Res., 94(C4), $4801-$ 4815

Weare, B. C. (1977), Empirical orthogonal analysis of the Atlantic Ocean surface temperatures, $O$. J.R. Meteorol. Soc., 103, 467-478.

Weisberg, R. H., and C. Colin (1986), Upper ocean temperature and current variations along the equator in the Atlantic Ocean during 1983-1984, Nature, 322, 240-243.

Weisberg, R. H., and Y. Tang (1987), Further studies on the response of the equatorial thermocline in the Atlantic Ocean to the seasonally varying trade winds, J. Geophys. Res., 92(C4), 3709-3727.

Weisberg, R. H., and Y. Tang (1990), A linear analysis of equatorial Atlantic Ocean thermocline variability, J. Phys. Oceanogr., 20, 1813-1825.

Weisberg, R. H., J. H. Hickman, T. Y. Tang, and T. J. Weingartner (1987) Velocity and temperature observations during the seasonal response of the equatorial Atlantic experiment at $0^{\circ}, 28^{\circ} \mathrm{W}, J$. Geophys. Res., $92(\mathrm{C} 5)$, $5061-5075$

Wyrtki, K. (1975), El Niño-The dynamic response of the equatorial Pacific Ocean to atmospheric forcing, J. Phys. Oceanogr, 5, 572-584. Xie, S.-P., and J. A. Carton (2004), Tropical Atlantic variability: Patterns, mechanisms, and impacts, in Earth's Climate: The Ocean-Atmosphere Interaction and Climate Variability, Geophys. Monogr. Ser., vol. 147 edited by C. Wang, S.-P. Xie, and J. Carton, pp. 121-142, AGU, Washington, D. C.

Zebiak, S. E. (1993), Air-sea interaction in the equatorial Atlantic region, J. Clim., 6, 1567-1586.

P. Brandt and V. Hormann, IFM-GEOMAR, Leibniz-Institut für Meereswissenschaften, Düsternbrooker Weg 20, D-24105 Kiel, Germany. (vhormann@ifm-geomar.de) 